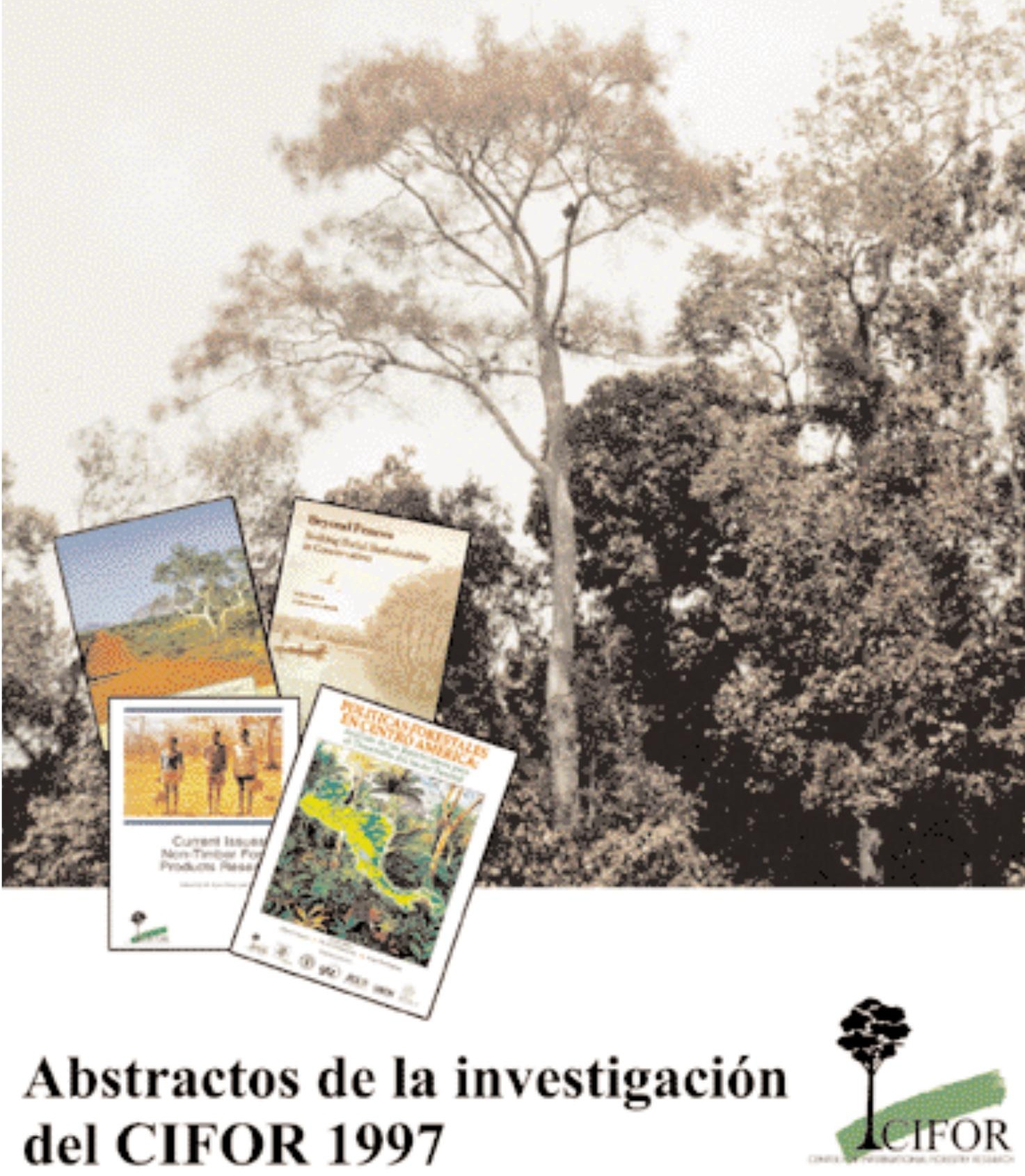




\section{Abstractos de la Investigación del CIFOR 1997}




\section{EI Sistema CGIAR}

El Grupo Consultivo para la Investigación Agrícola Internacional (CGIAR) es una asociación informal de donantes del sector público y privado (establecida en 1971), que apoya una red de dieciséis institutos internacionales de investigación agrícola, siendo el CIFOR el más reciente de estos. Los centros del CGIAR son parte de un sistema global de investigación agrícola, que aplica la capacidad científica internacional a la solución de los problemas de las personas menos favorecidas del mundo.

\section{CIFOR}

El Centro para Investigación Forestal Internacional (CIFOR) es un instituto de investigación científica global e independiente que utiliza lo mejor de la ciencia para resolver los problemas que afectan a los bosques tropicales y a las personas que dependen de ellos. CIFOR fue establecido en 1993, por el CGIAR, como respuesta a la preocupación global respecto a las consecuencias sociales, ambientales y económicas de la pérdida y la degradación de los bosques. Opera por medio de muchas alianzas descentralizadas con instituciones y/o individuos clave en los páises industrializados y en vías de desarrollo (incluyendo agencias gubernamentales, universidades, ONG e institutos de investigación del sector privado). La naturaleza y duración de esas asociaciones las determinan los problemas específicos de investigación que se están tratando. Esta agenda de investigación es revisada y acualizada periódicamente conforme los socios reconocen nuevas oportunidades y problemas.

El Centro para Investigación Forestal Internacional

Bogor, Indonesia

febrero 1999 


\section{Contenido}

1. Índice de Autores $\mathrm{V}$

2. Publicaciones del CIFOR (Publicaciones Internas) 1

3. Publicaciones del Personal del CIFOR

(Publicaciones Externas) 


\section{Índice de Autores}

\section{A}

Angelsen, $A$.

'La Tesis sobre el Ambiente y la Pobreza: ¿Estaba Brundtland Equivocado?"

\section{B}

Bertault, J.-G. y Sist, P.

Una comparación experimental de diferentes intensidades de cosechaaprovechamiento forestal usando aprovechamiento forestal de impacto reducido y aprovechamiento convencional en Kalimantán Oriental

Boyle, Timothy J.B. y Boontawee, Boonchoob (editores)

Medición y monitoreo de la biodiversidad en los bosques tropicales y templados

Boyle, T.J.B., Cossalter, C.C. y Griffin, A.R.

Recursos genéticos para las forestería de plantaciones forestales

Brown, A.G., Nambiar, E.K.S. y Cossalter, C.C.

Plantaciones para los trópicos - el papel que desempañan, su extensión y su naturaleza

Brown, A.G., Turnbull, J.W. y Booth, T.H.

El ambiente Australiano

Byron, $N$.

Retos y oportunidades: opciones de políticas para el sector forestal en la región Asia-Pacífico

Byron, $N$.

Asistencia para el desarrollo internacional en la forestería y el manejo de la tierraterrenos: el proceso y los participantes

C

CATIE y CIFOR

Manejo del bosque natural latifoliado en el trópico Americano: bibliografía 
Colfer, C.J. Pierce y Dudley, R.G.

Agricultores migratorios de Indonesia: ¿saqueadores o manejadores de los bosques? Producción de arroz y usos del bosque entre los Uma' Jalan de Kalimantán Oriental.

Colfer, C.J. Pierce con Peluso, N.L. y Chin See Chung

Más allá de la tumba y quema: manejo de los bosques del trópico húmedo de Borneo con base en el conocimiento indígena

Colfer, C.J. Pierce, Wadley, R.L., Woelfel, J. y Harwell, E.

Desde la corteza hasta el corazón del árbol: asuntos de género en el manejo sostenible de los bosques

Colfer, C.J. Pierce, Wadley, R.L. Woelfel, J. y Harwell, E.

Desde el corazón del árbol hasta la corteza en Indonesia: género y manejo sostenible de los bosques( parece esta repetido el título)

D

Doran, J.C. y Turnbull, J.W. (editores)

Árboles y arbustos australianos: especies para la rehabilitación de terrenos y plantación siembra de fincas en los trópicos

Doran, J.C., Turnbull, J.W. Martensz, P.N., Thomson, L.A.J. y Hall, N.

Introducción a un compendio de especies de Jong, $W$.

Desarrollo de la agricultura nómada y la amenaza de la pérdida de la biodiversidad

Dykstra, D. P. (editores)

Operaciones Forestales para la Forestería Sostenible en los Trópicos

Dykstra, D. P.

Antecedentes históricos y marco conceptual del código modelo de la FAO para la práctica del aprovechamiento forestal

Dykstra, D. P.

Sistemas de información en la forestería

Dykstra, D. P. y Heinrich, R.

Aprovechamiento forestal y sistema de transporte: Viejos problemas, nuevas soluciones 
Dykstra, D. P., Kowero, G. S., Ofosu-Asiedu, A. y Kio, P.

Promoción del manejo forestal en las zonas de bosque húmedodel tróopicaol húmedo del áfrica Occidental y Central Anglofonasajona

\section{F}

FAO, IUFRO, y CIFOR

Nuevos arreglos para la Ciencia Forestal. Un documento de discusión preparado para el Panel Intergubernamental sobre Bosques

Favrichon, V., Dupuy, B., Maitre, H. F., Nguyen-The, N., Damio, T., Doumbia, N., Kadir, K., Petrucci, Y. y Sist, P.

Respuesta del aprovechamiento de rodales delos bosques tropicales a las operaciones de silvicultura

G

Gillison, A.N.

Mapeo de la distribución potencial de las plantas y los animales para el manejo de la vida silvestre: uso del paquete de computación DOMAIN

Gillison, A.N. y Carpenter, G.

Conjunto de atributos funcionales de las plantas y gramática para la descripción y análisis dinámicos de la vegetación dinámica

Gillison, A.N., Schulze, W., Schulze, E.D. y Pate, J.S.

Abastecimiento de nitrógeno de los suelos y de los insectos durante el crecimiento de las "plantas jarrón": Nepenthes mirabilis, Cephalotus follicularis y Darlingtonia california

Gluck, P., Tarasofsky, R., Byron, N. y Tikkanen, I.

Opciones para el fortalecimiento del régimen legal internacionalo para los bosques

Goloubinoff, M., Katz, E. y Lammel, A. (editores)

Antropología del clima en el mundo hispanoamericano

Gregersen, H., Lundgren, A., Kengen, S. y Byron, $N$.

Medición y captura de los valores del bosque: temasasuntos para los que toman las decisiones 
Guariguata, M.R. y Dupuy, J.M.

Regeneración forestal en caminos abandonados de aprovechamiento forestal en las tierras bajas de Costa Rica

Guariguata, M.R., Chazdon, R.L., Denslow J.S., Dupuy, J.M. y Anderson, L.

Estructura y Florística de rodalescosechas secundarioas y de viejo crecimiento s viejos en las tierras bajas de Costa Rica

\section{H}

Hartati, N. S., Sudarmonowati, E., Fahdiar, A. y Siregar, U. J.

Seminario de la Asociación Indonesia de Biotecnología Agrícola (Garcinia mangostana, Parkia javanica, Nephelium lappaceum, y Artocarpus heterophyllus).

\section{I}

Ibach, Michael y Byron, Yvonne (editores)

Informe del foro de discusión sobre Servicios de Información en AsiaPacífico y el AGRIS/CARIS en el Siglo 21 - Una Consulta Regional Asia-Pacífico

\section{K}

Katz, E.

Cien años de cafetales. Dinámica de los agroecosistemas cafetaleros en la Mixteca (México)

Katz, E.

PNMB en Bulungan, Kalimantán Oriental, Indonesia

Katz, E.

Conferencia regional para el áfrica sobre conservación, manejo y utilización de las gomas vegetales, resinas y aceites esenciales

Katz, E.

Ritos, representaciones y meteorología en la Tierra de la Lluvia (Mixteca, México)

Katz, E. y Nguinguiri, J. C.

Las estrategias territoriales frente al estado: un ejemplo de apropiación del espacio en el Kouilou (El Congo) 
Kaimowitz, D.

Factores que determinan la baja deforestación: perspectiva desde el Amazonas de Bolivia

Kaimowitz, D.

Avance de la agricultura sostenible en América Latina

Kaimowitz, D.

Patrones de uso de la tierra y el manejo de los recursos naturales en Centroamérica

Kaimowitz, D.

Políticas que afectan la deforestación paraor causa de la ganadería en América Central

Kiekens, J. P. y Byron, R. N.

Cooperación forestal internacional: ¿ahora hacia adónde?

Kiker, C. F. y Putz, F. E.

Certificación ecológica de productos forestales: los retos económicos

Kowero, G.S. y Spilsbury, M.J.

Evaluación de la capacidad de investigación forestal enÁfrica Oriental y Meridional

Kowero, G.S. y Spilsbury, M.J.

Capacidad de la investigación forestal en la Comunidad de Sudafricana de Desarrollo en el Sur del África

\section{M}

Maogong, Z., Maoyi, F., Belcher, B. y Ruiz-Pérez, M.

Efectos de la Economía y las Políticas Sociales en los Sistemas de Manejo de la Producción - Un Estudio de Caso de las Industrias Chinas de Bambú

Midgley, S.J., Byron, R.N., Chandler, F.C., Ha Huy Thinh, Tran Vo Hung Son y Hoang Hong Hanh.

¿Necesitan las plantas pasaporte? Un estudio socioeconómico del papel que desempeñan el árbol exótico y otras especies de plantas en la provincia Quang Tri, Vietnam. 
Mittelman, A.J., Lai, C.K., Byron, N, Michon, G. y Katz, E.

Estudio de la perspectiva de los productos no maderables del bosque para Asia y el Pacífico: hacia el año 2010

Nasi, $R$.

Las poblaciones de Okoumés en Gabón. Su dinámica y crecimiento en las zonas costeras

Ndoye, O. y Ruiz-Pérez, $M$.

Mercados de los productos forestales no maderables del bosque en la zona de los bosques húmedos de Camerún

Ndoye, O., Ruiz Pérez, M. y Eyebe, A.

Mercados de los productos forestales no maderables del bosque en la zona de los bosques húmedos de Camerún( se repite dos veces, debe estar mal)

Nhantumbo, I., Dent, J.B., Kowero, G.S. y McGregor, M.J.

Beneficios no comercializables de los bosques que no se transan en el mercado: un enfoque de modelajeos para la intervención de políticas en Mozambique

\section{$\mathbf{O}$}

Old, K.M., See, Su Lee y Sharma, J.K.

Enfermedades de las Acacias Tropicales

Oreshkin, D.G., Skovsgaard, J.P. y Vanclay, J.K.

Estimación de la vitalidad de los brinzales árboles jóvenes para el de pino de Escoscia escocés (Pinus sylvestris L.) en la Karelia Rusa

\section{$\mathbf{P}$}

Paine, J.R., Byron, N. y Poffenberger, M.

Situación actual, tendencias y escenarios futuros para la conservación forestal incluyendo las áreas protegidas en la región Asia-Pacífico

Parrotta, J.A., Turnbull, J.W. y Jones, N.

Catalización de la regeneración de bosques nativos en tierrasenos tropicales degradadasgenerados 
Persson, R. y Janz, K.

Estimación y monitoreo de los recursos forestales y los bosques

Pinard, M. A. y Putz, F. E.

Monitoreo de los beneficios de la fijación de carbono asociados con un proyecto de aprovechamiento forestal de impacto reducido en Malasia

Prabhu, R. y Vanclay, J. K.

¿Cómo acertarle a un Blanco en Movimiento? La Sostenibilidad, las Personas y los Bosques

Putz, F. E., Elias, Sist, P., Dykstra, D.P. y Heinrich, R.

Métodos de investigación para el aprovechamiento forestal de impacto reducido: resultados del taller

\section{$\mathbf{R}$}

Ruiz-Pérez, M. y Arnold, J.E.M.

Temas actuales de la Investigación sobre los Productos No Maderables del Bosque

S

Sabogal, C., Camacho, M. y Guariguata, M. (editores)

Experiencias prácticas y prioridades de investigación en la silvicultura de bosques naturales en América Tropical

Saxena, N.C.

La Leyenda del Manejo Forestal Participativo en la India

Sayer, J.A., Vanclay, J.K. y Byron, N.

Tecnologías para el manejo sostenible de los bosques: retos para el Siglo 21

Segura, O., Kaimowitz, D. y Rodríguez, J. (editores)

Políticas forestales en Centroamérica. Análisis de las restricciones para el desarrollo del sector forestal

Sist, P. y Bertault, J.G.

El proyecto STREK 
Skovsgaard, J.P. y Vanclay, J.K.

Éxito en la regeneración y el crecimiento temprano de rodaleslevantamientos forestales

Smith, J., Sabogal, C., de Jong, W. y Kaimowitz, D.

Bosques Secundarios como Recurso para el Desarrollo Rural y la Conservación Ambiental en los Trópicos de América Latina

Sudarmonowati, E., Hartati, N. S. y Siregar, U. J.

65

Establecimiento de técnicas de marcadores genéticos bioquímicos para especies forestales tropicales de Shorea sp- especie de árbol del bosque tropical

Sunderlin, W. D.

Deforestación, medios de vida y las condiciones previas para el manejo sostenible en Olancho, Honduras

Sunderlin, W.D.

Una metodología ex-post para medir la participación de las personas pobres en la forestería social: un ejemplo de Java, Indonesia

Sunderlin, W.D.

Agricultura Migratoria Cultivos Alternativos y Deforestación en Indonesia: los pasos para aclarar la confusión en el debate

Sunderlin, W.D. y Gorospe, M.L.G.

Organizaciones de pescadores y modelos de co-gestiónmanejo conjunto:

el caso de la Bahía de San Miguel, Filipinas

Sunderlin, W.D. y Resosudarmo, Ida Aju

Tasas y Causas de la Deforestación en Indonesia: Hacia una Resolución de las Ambigüedades).

\section{$\mathrm{T}$}

Tomich, T.P., Kuusipalo, J., Menz, K. y Byron, N.

Aspectos económicos y políticos de la Imperata

Turnbull, J.W.

Vegetación Australiana

Turnbull, J.W. y Awang, K. 
Turnbull, J. W. y Byron, R. N.

Plantaciones de árboles tropicales para obtener productos de alto valor: una perspectiva del CIFOR

Turnbull, J.W. y Doran, J.C.

Eucalyptus urophylla

V

Vanclay, J.K.

Cambios y retos de la forestería internacional: preparándoseación para el Siglo 21

Vanclay, J.K.

FLORES: un modelo para evaluar opciones de uso de la tierra en la frontera del bosque

Vanclay, J.K.

¿Cómo obtener el máximo provecho de los datos de su parcela permanente?

Vanclay, J.K.

Introducción a la estimación de los rendimientos forestales

Vanclay, J.K.

Hacia una valoración más rigurosa de la biodiversidad

Vanclay, J.K.

TROPIS, el sistema de información sobre el crecimiento de los árboles y parcelas permanentes

Vanclay, J.K. y Skovsgaard, J.P.

Evaluación de modelos de crecimiento forestal

Vanclay, J.K., Gillison, A.N. y Keenan, R.N.

Utilización de los atributos no funcionales de las plantas para cuantificar la productividad del sitio y los patrones de crecimiento en bosques mixtos 
W

Wily, Liz

¿Cómo Encontrar el Marco Institucional y Legal Correcto para el Manejo Comunal de Bosques Naturales con base en las Comunidades? El Caso de Tanzania

Waldley, R.L., Colfer, C.J. Pierce y Hood, I.G.

La caza de primates y el manejo de bosques: el caso de los propietarios finqueros forestales de Iban en Kalimantán Occidental, Indonesia

Wibowo, D.H. y Byron, R.N.

Mecanismos de deforestación: una repaso encuesta

Wibowo, D.H., Tisdell, C.A. y Byron, R.N.

Deforestación y acumulación de capital: lecciones de la región alta del Alto Kerinci, Indonesia

Wollenberg, E.

Toma de decisiones entre diversos intereses: el uso de escenarios futuros en las políticas de manejo forestal local: una propuesta metodológicaogía propuesta

Wollenberg, E. y Colfer, C.J.P.

Sostenibilidad social

Z

Zuidema, Pieter A., Sayer, Jeffrey A. y Dijkman, Wim

Fragmentación forestal y biodiversidad forestal: el caso de las áreas de conservación de tamaño intermedio 
Medición y Monitoreo de la Biodiversidad en los Bosques Tropicales y Templados.

Boyle, Timothy J.B. y Boontawee, Boonchoob (editores)

Muchas estimaciones sugieren que los bosques del mundo son el hogar de más del $50 \%$ de la biodiversidad terrestre, sin embargo los bosques templerados y tropicales enfrentan numerosas amenazas, que incluyen la expansión agrícola e industrial, el cambio climático, el manejo no sostenible y la contaminación. Para conservar los bosques y la diversidad de sus organismos vivientes, es necesario medir y monitorear la biodiversidad, de manera que se pueda evaluardeterminar el impacto de las actividades humanas y la eficacia de las medidas de conservación. Puesto que el concepto de la biodiversidad cubre el rango de la vida misma, desde los genes hasta los ecosistemas, la medición y el monitoreo son extremadamente complicados.

Este libro contiene 24 documentos seleccionados de los que fueron presentados en el Simposio de la IUFRO sobre el tema "Medición y Monitoreo de la Biodiversidad en los Bosques Tropicales y Templados", patrocinado por el Departamento Forestal Real de Tailandia, en Chiang Mai, del 27 de agosto al 2 de setiembre de 1994. La selección de los documentos se hizo de manera que se le diera la más amplia cobertura posible a aspectos clave, que incluyen Principios para la Medición y el Monitoreo de la Biodiversidad (8 documentos), Diversidad Genética (6 documentos), Diversidad de Especies y de Ecosistemas (5 documentos) y Metodología (5 documentos). Los árboles de los bosques son el tema de muchos de los documentos, pero también se incluyen documentos que tratan sobre la diversidad de artrópodos, micro-hongos, pájaros y mariposas, gibones y otros que tratan sobre la gama completa de la biodiversidad.

1995, 240 pág., US\$10 (2da impresión).

ISBN 979-8764-01-3

\section{Nuevos Arreglos para la Ciencia Forestal.}

FAO, IUFRO, y CIFOR

Conforme los científicos forestales amplían su campo visual y pueden percibir los problemas de una forma que abarque todo el sector, y con un 
sentido de historia, comenzarán a preguntar y a responder más a las preguntas más urgentesde presión. Si adoptan un enfoque que sea más analítico que descriptivo, obtendrán muchos resultados nuevos. El nuevo ambiente de políticas en que tiene que operar la ciencia forestal ahora refleja una creciente preocupación sobre el cambio ambiental, a nivel local y global, y la necesidad de controlarlo mediante un mayor desarrollo más sostenible. El centro del problema estriba en lograr un balance entre las necesidades de todas las personas y; reconocer que los cambios en la salud del bosqueforestal tienen múltiples impactos, tanto en el ambiente local como en el global. Los bosques son una parte clave de la interfazinterfase entre la humanidad y el ambiente. Ya no pueden seguir siendsoer estudiados, como si fueran puesto que son simplemente "fábricas al aire libreexteriores para producir fibras de madera", divorciados de la sociedad y como si las actividades forestales fueran únicamente una preocupación local. En el mundo real, los bosques juegan un papel fundamental en la sociedad y pueden tener impactos a todos los niveles. Conforme más científicos forestales y otras personas, aprecien esto, el mundo se dará cuenta de la verdadera importancia de los bosques y de su papel central en el desarrollo sostenible.

En forma colectiva, la IUFRO, la FAO y el CIFOR presentan una excelente oportunidad para que garantizarce que las prioridades de los clientes, en cuanto a la investigación forestal, se identifiquen correctamente y que se les responda en la forma apropiada.

Un documento de discusión preparado para el Panel Intergubernamental sobre Bosques. Cuarta Sesión, Nueva York, febrero de 1997, 17 pág.

Informe del Foro de Discusión sobre Servicios de Información en Asia-Pacífico y el AGRIS/CARIS en el Siglo 21 - Una Consulta Regional Asia-Pacífico.

Ibach, Michael y Byron, Yvonne (editores)

La información disponible para los investigadores en el mundo actual y la tecnología para tener acceso y utilizar dicha información se expanden rápidamente. Lamentablemente, la mayoría de las organizaciones forestales y de investigación forestal en la región Asia-Pacífico ni tienen 
acceso ni pueden utilizar en forma eficiente, en la toma de decisiones, la vasta cantidad de información existente. en la toma de decisiones.

Una serie de organizaciones en la región comparten objetivos comunes para desarrollar la capacidad de investigación forestal del sector. Con este fin, representantes del Proyecto ASEAN del proyecto Centro de Semillas de árboles Forestales del ASEAN (AFTSC), del ASEAN Instituto de Manejo Forestal del ASEAN (AIFM), del Centro para la Investigación Forestal Internacional (CIFOR), del Centro Internacional de Investigación y Desarrollo de Canadá (IDRC) y del CAB Internacional (CABI) y el Programa de Apoyo a la Investigación Forestal para Asia y el Pacíifico (FORSPA) propusieron soluciones a través de actividades de colaboración. Este informe es el acta del foro de discusión sobre Servicios de Información en Asia-Pacífico celebrado en Bogor, Indonesia, del 30 de octubre al 1 de noviembre de 1996. La lista de necesidades generadas a partir de una encuesta preliminar guiaron las deliberaciones del foro. Los participantes identificaron metas prioritarias, planes de acción para su logro y agentes/agencias responsables, rangos de tiempo esperados y costos probables.

El Sistema Integrado de Información para las Ciencias y la Tecnología Agrícolas (AGRIS) y el Sistema de Información de Investigación Agrícola Actual (CARIS) son parte de la una red más amplia de la FAO que provee una extensa base de datos de información a nivel mundial sobre investigación en agricultura y asuntos relacionados. Para tratar el asunto del AGRIS/CARIS en el Siglo 21, se celebró una Consulta Regional AsiaPacífico conjuntamente con el foro de discusión. Este informe documenta las discusiones diseñadas para orientadas a incrementar las actividades de cooperación y desarrollar nuevos enfoques para mejorar la cobertura de la literatura forestal en el AGRIS y la información sobre investigación forestal en CARIS entre los países en la región Asia-Pacífico; también revisa los nuevos desarrollos tecnológicos de la información y sus impactos en los proveedores y los usuarios de la información. Se recomendó una revisión detallada independiente para evaluar el AGRIS y el CARIS y su dirección futura en el Siglo 21, con especial atención a la cobertura de la información forestal.

Trabajo Ocasional No. 10, 1997, 106 pág. 
Capacidad de la Investigación Forestal en la Comunidad de Desarrollo en el Sur delde áfrica Meridional.

Kowero, G.S. y Spilsbury, M.J.

En 1995, se llevó a cabo una encuesta sobre la capacidad de investigación en las instituciones que desarrollan investigación relacionada con la forestería en los países de la Comunidad Sudafricana de Desarrollo (SADC). Este documento presenta una revisión de los métodos disponibles para valorar la capacidad de investigación y resume los esfuerzos previos para valorar la capacidad de investigación en la región.

La metodología adoptada utiliza indicadores comunes, por lo que permite las comparaciones entre instituciones. Los resultados de la encuesta se discuten y se vuelve a enfatizar sobre la necesidad de priorizar el reclutamiento, el entrenamiento y el desarrollo del personal científico; potencial humano disponible; solamente cerca de la mitad de los científicos que desarrollanhacen investigacioónesn forestales la forestería y sobre los temasasuntos relacionados tienen el suficiente entrenamiento y exposición científica. La gerenciaEl manejo de la investigación es otro área que requiere de atención urgente para minimizar los impactos negativos de muchas de las externalidades económicas yasí como de otro tipo, que afligen la investigación en la región. Cerca del 17\% y el 28\% de las instituciones encuestadas destinaron más del $20 \%$ de sus presupuestos y del tiempo de su personal, respectivamente, a los grupos de usuarios. Esto planteaderiva algunas preguntas sobre la forma en que se formulan las prioridades de investigación y la importancia de la investigación en proceso.progreso. Existe una interacción considerable entre las instituciones en la región, pero aún no está clara la forma en que esto se puede traducir en actividades coordinadas de colaboración.

También se presenta la metodología para evaluar la capacidad de investigación. A pesar de que los indicadores de los diversos parámetros de la capacidad de investigación no captan la totalidad de las implicaciones de la capacidad, suministranfacilitan una perspectiva útil sobre la capacidad local para emprender la investigación forestal en áfrica del Sur y delel Este del África.

Trabajo Ocasional No. 11, 1997, 45 pág. 


\section{Enfermedades de las Acacias Tropicales.}

Old, K.M., See, Su Lee y Sharma, J.K.

Las acacias tienen una considerable importancia social e industrial en la reforestación tropical y se espera que cerca de 2 millones de hectáreas sean plantadas sembradas en Asia del Sudeste, para el año 2000. En la actualidad, las especies de acacia de mayor interés para la forestería de plantaciones en los trópicos son nativas del norte de Australia, de Papua Nueva Guinea y de Irian Jaya.

Informes recientes de Malasia, Indonesia, Tailandia y del norte de Australia sugieren que la productividad futura de las plantaciones de acacia podrían verse afectadas por hongos patógenos que incluyen la mancha de las hojas, roya del ápice, chancro del tallo, pudrimiento del corazón y roya de la agalla. En 1995-96, patólogos forestales desarrollaron una serie de levantamientosencuestas sobre enfermedades en rodales nativos, cosechas y ensayos nativos australianos, en plantaciones forestales sociales y operacionales de acacias tropicales en Australia, India, Indonesia, Malasia y Tailandia, para evaluar los hongos patógenos como una amenaza potencial para el crecimiento y la productividad de la acacia tropical, así como la importancia relativa de patógenos fungosos individuales. Las especies de árboles incluidas en loas levantamientos encuestas fueron la Acacia mangium y la A. auriculiformis, sobre la base de su actual importancia como especies de plantaciones. También se evaluaron la A. crassicarpa y la A. aulacocarpa, puesto que, a pesar de haber sido plantadas hasta el momento únicamente en a pequeña escala hasta el momento, están incluidas en ensayos de procedencia y especies en muchos sitios a través de la región. Los científicos que participaron en el proyecto se reunieron con los gerentes de investigación de las cinco compañías de pulpa y de papel de plantaciones más importantes de Indonesia y con las empresas comercialesde negocios del gobierno, del 23 de abril al 3 de mayo de 1996 en el campo de base de PT Musi Hutan Persada Subanjeriji, en el Sur de Sumatra, para presentar los resultados de loas levantamientos encuestas. Esta publicación es un informe de estado sobre las enfermedades de las acacias en varios países, con base en la información presentada durante el taller. Provee una línea de basemarca del conocimiento actual de la patología de las cuatro especies más importantes de Acacia que crecen actualmente en plantaciones en las áreas tropicales del Sudeste de Asia, el Subcontinente Indio y el Norte de Australia. 
Las encuestas y los talleres fueron posibles gracias al financiamiento del Centro Australiano para la Investigación Agrícola Internacional (ACIAR), del Centro para la Investigación Forestal Internacional (CIFOR) y al apoyo de las organizaciones de los científicos participantes.

Publicación Especial, 1997, 120 pág.

ISBN 979-8764-13-7

\section{Temas actuales de la Investigación sobre los Productos No Maderables del Bosque. \\ Ruiz-Pérez, M y Arnold, J.E.M. (editores)}

Este libro contiene una serie de documentos de basefondo comisionados que fueron presentados en el taller sobre 'Investigación de Productos No Maderables Del Bosque“ (celebrado en Hot Springs, Zimbabwe, del 28 de agosto al 2 de setiembre de 1995). Mediante la reunión de experiencias de diferentes regiones y de antecedentes profesionales, el libro intenta analizar la complejidad de los usos múltiples de los bosques desde una perspectiva multidimensional que incorpora factores ambientales, sociales, económicos, tecnológicos, de políticas, históricos y culturales.

Se revisan asuntos actuales de discusión. Estos incluyen la posibilidad de hacer consistentesparear las agendas de la conservación y del desarrollo, mediante la promoción de los PNMB como lo proponen una serie de iniciativas, el senderocamino unidireccional del desarrollo desde la extracción a la producción agrícola intensiva, los papeles que desempeñan los PNMB en la s estraestrategias de subsistencia de las gentepersonas, las diferenciaciones internas entre las comunidades, las diferentes formas de acción adoptadas para asegurar la tenencia y sus efectos divergentes, así como el significado y la conveniencia de usar PNMB como una categoría analítica.

Una conclusión general que puede ser extraída del libro es la necesidad de construir una agenda de investigación interdisciplinaria, así como emplear más de un enfoque o método para tratar las situaciones complejas que caracterizan los usos múltiples de los bosques.

1996, 264 pág., US\$15. 


\section{La Leyenda del Manejo Forestal Participativo en la India.}

Saxena, N.C.

Después de cerca de 100 años de control gubernamental exclusivo, los bosques en la India están siendo manejados cada vez más con la participación de las gentepersonas. Casi todos los estados han aprobado resoluciones permisivas para facilitar lo que ahora se llama popularmente el programa de Manejo Forestal Conjunto (JFM). Sin embargo, su implementación hasta la fecha ha sido dispareja. Los oficiales de campo por lo general están renuentes a compartir el poder y la autoridad con las gente personas, mientras tienen la expectativa que esperan de que estos protejan los bosques sin remuneración. Tampoco es muy conocido bajo qué condiciones tiene éxito el JFM, y si estas condiciones son internas o si son más influenciadas por las políticas gubernamentales.

Con base en las repetidas visitas del autor a las aldeas del JFM, en varios estados de la India, este libro suministrafacilita una crítica de las políticas forestales pasadas y presentes, revisa la implementación del manejo forestal participativo en cinco estados de la India, explica porqué la acción comunal se mantiene a través del tiempo, y esboza sus conclusiones en la teoría más amplia de los regímenes de propiedad.

El libro pretende sintetizar diversas experiencias sobre participación y vincula las hipótesis de participación y vínculos de acción colectiva con evidencia empírica. Es uno de los primeros libros de base para el Manejo Forestal Conjunto, y será de gran valor para las agencias donantes, los gobiernos estatales, los formuladores de políticas y los investigadores en los programas de desarrollo participativo.

Publicación Especial, 1997, 214 pág.

ISBN 979-8674-15-3

\section{Tecnologías para el manejo sostenible de los bosques: retos para el Siglo 21.}

Sayer, J.A., Vanclay, J.K. y Byron, N.

La tecnología ayudará a tratar los retos de la forestería sostenible en el Siglo 21. Algunos de esos retos incluirán el cambio de la producción de los bosques nativos hacia las plantaciones en áreas de ventajas comparativas, procesos más eficientes que desvinculan los productos de uso final de las 
características de la madera en bruto, demanda creciente, mejores tecnologías de información para apoyar a los que toman las decisiones y más opciones para conservar la biodiversidad. Las definiciones sobre sostenibilidad variarán en el tiempo y el espacio, conforme cambien las expectativas y las aspiraciones de la sociedad, por lo que no puede existir una 'bala de plata' que garantice la sostenibilidad. No obstante, el progreso se puede facilitar con un enfoque sistemático del manejo forestal, que abarca el ciclo usual de la planificación: formulación de objetivos, preparación de la estrategia, planificación, implementación, monitoreo y evaluación. Esto requiere de una buena comprensión de cada situación particular. La gerencia necesita de buenos recursos para la evaluación y sistemas de apoyo para la toma de decisiones; debe fomentar la participación de los actores en la toma de decisiones, los costos y los beneficios; y asegurar los procedimientos efectivos para la resolución de los conflictos. Dentro de un sistema apropiado, los avances técnicos, tales como mejores máquinas y nuevos implementos podrían ayudar a marcar la diferencia, pero no podrán garantizar por sí mismos la sostenibilidad. Las tecnologías importantes para la forestería sostenible son aquellas que promueven una mejor comunicación entre los actores y permiten decisiones informadas que abarcan escalas desde el gen hasta el ecosistema. Este sigue siendo un reto importante para los manejadores de los bosques en su busca por la sostenibilidad.

Trabajo Ocasional No. 12, 1997, 11 pág

Bosques secundarios como recurso para el desarrollo rural y la conservación ambiental en los trópicos de América Latina.

Smith, J., Sabogal, C., de Jong, W. y Kaimowitz, D.

Datos recientes muestran que la destrucción de los bosques primarios ha estado acompañada por la expansión de los bosques secundarios. Los estudios también muestran que los bosques secundarios son capaces de proporcionar algunos de los servicios económicos y ecológicos de los bosques primarios. Esto ha conducido a una nueva estrategia para aumentar el valor de los bosques secundarios para los agricultores y ganaderos, con el objetivo de inducirlos a conservar estos bosques indefinidamente, o al menos a retardar su reconversión a otros usos. El objetivo de este artículo es de contribuir a una estrategia coherente para 
realizar el potencial de los bosques secundarios. Nuestra hipótesis es que existen áreas importantes bajo bosque secundario en terrenos de pequeños y grandes productores y que, a través de intervenciones tecnológicas y de política, se puede incrementar significativamente el área y el valor económico y ecológico de los bosques secundarios y, por consiguiente, el periodo período por el cual estos son conservados. También, formulamos la hipótesis de que los bosques secundarios son altamente variables en sus características ecológicas y en términos de objetivos y recursos de sus propietarios. Por tanto, es probable que las intervenciones requeridas sean altamente variables. Un análisis de la dinámica de los bosques secundarios puede ayudar a dirigir las intervenciones a aquellas áreas con la más alta probabilidad de impacto. El análisis de los aspectos socioeconómicos de la dinámica de bosques secundarios se basa en el cambio progresivo en el tiempo de algunas características de las zonasáreas de la frontera agrícola. Hacemos la distinción entre dos trayectorias diferentes: aquella seguida por colonos y la de comunidades indígenas. Una tercera categoría de circunstancias accidentales, tales como conflictos militares y litigio, también pueden conducir a la creación de bosques secundarios.

Las opciones de manejo para bosques secundarios se clasifican de acuerdo con sus requerimientos de recursos (capital, tierra, mano de obra y capacidad gerencial) y el transcurso de tiempo para obtener un producto, resultando cuatro grupos: barbechos mejorados de ciclo corto, barbechos enriquecidos de ciclo medio, bosques de producción de ciclo medio a largo, y bosques de conservación. Las características de cada categoría de productores y sus bosques secundarios seon contrastadosmparan con las características de las opciones de manejo donde la probabilidad de adopción es la más alta.

Luego, se identifican las categorías generales de intervenciones de política apropiadas para cada categoría de productor, siendo: políticas relacionadas con el mercadeo de productos del bosque secundario, reformas de la legislación y políticas que permiten a los productores capturar el valor de los servicios ambientales que suministran los bosques secundarios.

Concluimos enfatizando la importancia de un marco conceptual dinámico para el desarrollo de una estrategia para bosques secundarios, que permite prevenir la degradación del recurso, en oposición a revertir 
ésta después de que ocurra. El marco conceptual que se presenta también permite el análisis de bosques secundarios como una parte integral del sistema de producción del agricultor. Finalmente, se enfatiza que la contribución principal de este ejercicio es el marco conceptual. Los resultados son meramente indicativos y necesitan ser verificados con datos empíricos.

Trabajo Ocasional No. 13, 1997, 30 pág

\section{Tasas y Causas de la Deforestación en Indonesia: Hacia una Resolución de las Ambigüedades.}

Sunderlin, W.D. y Resosudarmo, Ida Aju

Durante los últimos años, se han desarrollado varios esfuerzos importantes de investigación sobre la tasa y las causas de la deforestación de Indonesia, así como mucha literatura relacionada, pero todavía no existe consenso en la comunidad de investigación sobre estos temas. Este documento revisa las áreas de incertidumbre y confusión, y propone preguntas que deben ser respondidas para obtener una mejor comprensión sobre el tema. Entre las principales preguntas se encuentran: (1) ¿Cómo vamos a definir 'bosques', ‘deforestación' y 'agencia' dentro del contexto de Indonesia? (2) ¿Cuáles son las características socioeconómicas y las prácticas de uso de la tierra de los diversos agentes que han sido agrupados bajo el término “agricultura migratoria"? (3) ¿Es la relación entre el aumento de la densidad de la población y la pérdida de la cobertura forestal causal o incidental? (4) ¿Porqué parece que algunos concesionarios manejan sus áreas relativamente bien, mientras que otros no lo hacen? (5) ¿Cuáles han sido los efectos netos en la cobertura forestal como consecuencia de la reestructuración macroeconómica y de los cambios en los precios de los productos desde inicios de los años ochenta? Se proponen lineamientos para mejorar la investigación sobre la tasa y las causas del cambio en la cobertura forestal. El documento termina remarcando la necesidad de superar la tendencia por buscar explicaciones mono-causales. Las explicaciones convincentes serán necesariamente complejas, puesto que las causas residen en fuerzas socioeconómicas duraderas y vastas. 
¿Cómo Encontrar el Marco Institucional y Legal Correcto para el Manejo Comunal de Bosques Naturales con base en las Comunidades? El Caso de Tanzania.

Wily, Liz

Conforme aumenta y madura la participación de la comunidad en el manejo de los bosques naturales, también se vuelve más apremiante la necesidad de establecer los derechos y las obligaciones, tanto del Eestado como de la comunidad, en marcos institucionales trabajables de trabajo y legalmente obligatorios. Esto, en particular, donde se están redistribuyendo el poder y la autoridad.

Esta publicación hace referencia específica a Tanzania, en forma específica, donde a las comunidades forestales locales se les están empezando a ser designadasr como las autoridades a cargo del manejoadministradoras de determinados terrenos forestales y, en algunos casos, hasta como sus dueños. Los resultados positivos le están dando un apoyo considerable al manejo basado en las comunitarioidades como la estrategia de manejo forestal a elegir. Su implementación también ha impulsado por necesidad la búsqueda de mecanismos accesibles mediante los cuales se pueda implantarembestir legalmente la autoridad comunitaria.

El autor argumenta que, a este respecto, Tanzania tiene una ventaja por sobre otros estados africanos del Sub-Sahara, por la forma poco usual de identidad legal otorgada a las comunidades rurales y al apoyar leyes administrativas y territoriales que otorgan el control del manejo de los recursos naturales a lascon base en las aldeas. Algunos elementos específicos que se exploran incluyen el hecho de que las aldeas rurales en Tanzania son reconocidas como un nivel de gobierno formal, investidasembestidas por lo tanto de ciertos derechos y obligaciones; que la aldea rural puede optar por una situación legal corporativa, permitiéndole, inter alia, poseer y manejar propiedades con responsabilidaden forma responsable ante una corte legal; y que la ley de propiedad facilita una versión estatutaria moderna de la tenencia comunitaria, dentro de los límites y la responsabilidad de una persona legal privada.

Wily brinda una guía detallada de la forma como una comunidad adyacente al bosque puede asegurar la custodia de un bosque natural local, 
sea que ya esté declarado oficialmente como una Reserva Forestal o como un bosque de propiedad pública, y se le otorgue la responsabilidad de su correcto manejo conservacionista.

Publicación Especial, 1997, 57 pág. ISBN 979-8764-16-1 


\section{'La Tesis sobre el Ambiente y la Pobreza: ¿Estaba Brundtland Equivocado?"}

Angelsen, $A$.

La tesis sobre el ambiente y la pobreza sugiere que los pobres son tanto los agentes como las víctimas de la degradación ambiental. A pesar de que la tesis haya sido necesaria para evitar una confrontación Norte-Sur sobre aspectos ambientales, su validez podría ser cuestionada. Se argumenta que la coexistencia de la pobreza y la alteración ambiental podría verse, en forma más apropiada, como la consecuencia conjunta de limitadas oportunidades para algunos grupos, procesos de desarrollo disparejos y una distribución desigual de los derechos y el poder, así como políticas mal dirigidas. En muchos casos, mayores ingresos aumentan la presión sobre el ambiente. Este será en particular el caso cuando las inversiones y los insumos adquiridos mediante lapor compragresos provenientes de las ventas se usen para aumentar la capacidad para explotar los recursos naturales y cuando la contaminación se relacione con el uso de combustibles fósiles.

Forum for Development Studies 1: 135-54.

Una comparación experimental de diferentes intensidades de cosecha usando aprovechamiento forestal de impacto reducido y aprovechamiento convencional en Kalimantán Oriental.

Bertault, J.G. y Sist, P.

El aprovechamiento forestal se investigó tanto en términos del volumen comercial de la madera extraída como el impacto en el rodallevantamiento remanente. Las técnicas de aprovechamiento forestal convencional (AFC) y las de aprovechamiento forestal de impacto reducido (AFIR) se compararon sobre la base de los inventarios de los rodaleslevantamientos antes y después de la cosecha. El volumen de la madera extraída promedió $87 \mathrm{~m}^{3}$ ha-1 y el volumen comercial resultante fue de $46 \mathrm{~m}^{3}$ ha-1 (p.e., el $53,7 \%$ del volumen tumbado). En promedio, el aprovechamiento forestal dañó el $40 \%$ de los árboles residuales (diámetro a la altura de pecho (dap) superior a los $10 \mathrm{~cm}$ ); se registraron árboles dañados y muertos en proporciones equivalentes ( $21 \%$ y $19 \%$, respectivamente). Por lo general, las operaciones de tumba causaron daños a los árboles, siendo el daño de 
la corona el más común, mientras que el arrastre causó la muerte de árboles, sobre todo a causa del desarraigamiento la extirpación. Los daños y la muerte de los árboles causados con el AFIR, fueron substancialmente menores $(30,5 \%)$ que los métodos convencionales $(48,1 \%)$. Este estudio demostró que el impacto del aprovechamiento forestal se puede reducir notablemente con supervisión estricta y planeación de las operaciones de aprovechamiento, así como mediante la limitación de la intensidad de la cosecha, que no debería exceder los $80 \mathrm{~m}^{3}$ ha-1. Si se siguen estas recomendaciones técnicas, se puede reducir el daño en un $20 \%$, lo que equivale a cerca de 100 árboles tallos hha-1 (dap superior a los $10 \mathrm{~cm}$ ).

Forest Ecology and Management. 94: 209-18.

Recursos genéticos para las forestería de plantaciones forestales. En: Nambiar, E.K.S. y Brown, A.G. (editores). Management of soil, nutrients and water in tropical plantation forests, 25-63.

Boyle, T.J.B., Cossalter, C.C. y Griffin, A.R.

Relativamente pocas especies tropicales han sido usadas en forma extensiva en las plantaciones. En casi la tercera parte del área total de las plantaciones forestales tropicales, se usan especies de pinos y eucaliptos, y comúnmente también se siembran acacias. Al utilizar efectivamente los recursos genéticos, es importante valorar la contribución relativa del genotipo y del ambiente al fenotipogenotipo, y la magnitud relativa de la variación genética en cada nivel de la jerarquía genética: las especies, las procedencias y hasta los árboles individuales. Se discute sobre el significado de la variación cuantitativa y la genética molecular en la selección de los recursos genéticos y los usos de estos diferentes tipos de información en el diseño e implementación de las estrategias descritas para el mejoramiento de los árboles. Se revisan diferentes enfoques de la selección de los recursos genéticos en cada nivel de la jerarquía genética, con especial referencia a la selección del uso eficiente del agua y los nutrientes. Mientras que la selección (ayudada de un marcador), los ensayos y el modelaje fisiológicos podrían ser de valor en el futuro, las pruebas de campo tradicionales siguen siendo una necesidad absoluta. 
Plantaciones para los trópicos - el papel que desempañan, su extensión y su naturaleza. En: Nambiar, E.K.S. y Brown, A.G. (editores). Management of soil, nutrients and water in tropical plantation forests, 1-23.

Brown, A.G., Nambiar, E.K.S. y Cossalter, C.C.

Este capítulo describe el contexto en el cual las plantaciones forestales tropicales se expanden como una fuente de madera industrial y de combustible. La demanda mundial de estos productos está aumentando, pero la tasa del aumento está disminuyendo y depende de las fluctuaciones en la actividad económica. En muchos países, la dependencia de madera para leña es muy ajustada, y no está disminuyendo en absoluto. El uso de árboles de plantaciones por parte de las comunidades y de la industria, para satisfacer estas demandas está aumentando. Una pequeña cantidad de especies han sido usadas muy extensamente, pero hay ventajasque darles a los productores el mérito de en extender la variedad disponible de escogencia para los productores, en parte paraor satisfacer mejor las necesidades desde abastecerse de los diversos ambientes biofísicos y socioeconómicos de los países tropicales. Los muy diversos climas y suelos de los trópicos se reflejan en la gran variación de los rendimientos de las plantaciones, y todavía quedan por entenderse muchos asuntos críticos relativos a la producción sostenible de las plantaciones tropicales. Muchos de los factores que causan la baja productividad son fáciles de manipular a través del manejopor parte de la gerencia. La experiencia de las regiones templadas puede brindar una valiosa guía para la práctica así como para la investigación en los trópicos. Los requerimientos de madera no se pueden satisfacer únicamente a partir de los bosques nativos; las plantaciones ofrecen perspectivasrospectos probadasdemostrables de mayores tasas de producción por unidad de superficieárea en comparación con los bosques nativos, y las tendencias de producción sugieren que hasta los países ricos en bosques están cambiando su dependencia en el abastecimiento de madera de los bosques nativos a las plantaciones. La producción a largo plazo que requiere de cuidados ambientales es un reto tanto para la investigación como para la práctica.

Monografia de ACIAR No. 43. ACIAR con CSIRO y CIFOR, Canberra, Australia. 
El Ambiente Australiano. En: J.C. Doran y Turnbull, J.W. (editores). árboles y arbustos australianos: especies para la rehabilitación de terrenos y siembra de fincas en los trópicos. 1-18.

Brown, A.G., Turnbull, J.W. y Booth, T.H.

El volumen está diseñado para brindar un texto de referencia a todas aquellas personas involucrados en la selección y producción de árboles y arbustos en las zonas rurales de los países en vías de desarrollo y en las áreaspartes más tropicales de Australia. El propósito de este primer capítulo es brindar una introducción a las principales características del ambiente australiano, dentro del cual han evolucionado los árboles y arbustos descritos en el libro.

El énfasis recae en esos factores del ambiente para los cuales parece haber datos disponibles en situaciones de campo en otros países donde se usan los árboles y arbustos australianos, facilitando así la selección inicial de especies a través del uso de homoclimas. Dicha información tiene un valor predictivo mucho mayor que la ocurrencia observada en forma natural observada, que puede estar limitada por varios factores, tales como los incendios el fuego y la competencia, que a cambio pueden cambiar y no proveen ninguna indicación de adaptabilidad o plasticidad de especies potencialmente útiles. Debido a que la disponibilidad de la humedad y la temperatura son influencias muy importantes en la sobrevivencia y crecimiento de las plantas, este capítulo se concentra ens estos factores.

Monografía de ACIAR No. 24. ACIAR, Canberra, Australia.

\section{Retos y oportunidades: opciones de políticas para el sector forestal en la región Asia-Pacífico.}

Byron, N.

Se analizan los principales temasasuntos de políticas y oportunidades que confrontan a los gobiernos en la región Asia-Pacífico, al tratar de alcanzar el uso y manejo sostenible y equitativo de sus bosques. El documento identifica las tendencias en el sector forestal y sus más amplias y subyacentes causas económicas, demográficas y sociales, particularmente con respecto a quién manejará cuáles bosques en el futuro y con qué 
propósitos. Estos factores incluyen las presiones por la descentralización, la corporativización, la privatización y la devolución a los grupos comunitarios locales, como parte de movimientos extendidos haciaa los gobiernos más pequeños 'que se concentran en dirigir el bote, en vez de remarlo'.

El documento enfatiza el significado social y económico actual de los bosques para las gentepersonas que viven en/cerca de los bosques tropicales en la región de Asia-Pacífico, y sugiere posibilidades para mejorar las condiciones sociales, económicas y ambientales de los bosques y de loas personas que viven en/cerca de ellos.

Se examinan algunas de las oportunidades de desarrollo en el sector forestal, incluyendo los posibles intercambios a largo plazo entre los objetivos y las necesidades económicas, sociales y ambientales. Se examina también el potencial de la negociación de resultados 'ganargasnardores' y opciones de reformas políticas e institucionales por parte de los gobiernos nacionales en la región Asia-Pacífico, y cómo éstas podrían reforzarse con los esfuerzos internacionales.

Estudio sobre la perspectiva del sector forestal de Asia-Pacifico. Documento de Trabajo Serie No. APFSOS/WP/09. Oficina Regional de la FAO para Asia y el Pacífico Bangkok, Tailandia. 64 pág.

\section{Asistencia para el desarrollo internacional en la forestería y el manejo de la tierraenos: el proceso y los participantes.}

Byron, N.

“¿Porqué fracasan tantos proyectos de ayuda forestal?” es la pregunta que se hace más frecuentemente. La mayoría de las respuestas detallan las dificultades técnicas de la implementación.

Sin embargo, este documento argumenta que la respuesta sólo se puede encontrar mediante la comprensión de dos procesos mucho más generales; cómo se relaciona una actividad forestal con un contexto socioeconómico mucho más amplio en el cual está sumergido; y cómo funciona en la práctica la asistencia para el desarrollo. Muchos proyectos que loscuyos profesionales forestales ven como fracasos, en términos técnicos y hasta humanitarios, podrían haber sido vistos como tenido éxitos de acuerdo con 
otros criterios políticos o comerciales, o con las pruebas de otros grupos de interés. A pesar de las restricciones inherentes en el proceso del desarrollo internacional, muchos proyectos forestales han brindado en forma exitosa beneficios reales y duraderos a las sociedades, a las economías y al ambiente., en forma exitosa. Los proyectos, especialmente aquellos de carácter socioforestal, continuarán fracasando, si su diseño e implementación no le prestan atención a las necesidades del grupo meta, los pobres.

Commonwealth Forestry Review 76: 61-8.

\section{Manejo del bosque natural latifoliado en el trópico americano: bibliografía.}

\section{CATIE y CIFOR}

Como una manera de contribuir a una mayor diseminación y utilización de la información disponible en la Región, el Centro para la Investigación Forestal Internacional - CIFOR y el Centro Agronómico Tropical de Investigación y Enseñanza - CATIE decidieron unir esfuerzos para iniciar la compilación de una bibliografía anotada sobre temas relacionados con el manejo de bosques naturales en América Tropical. Después de más de año y medio de arduo trabajo divulgativo, de compilación, procesamiento y revisión, tenemos la satisfacción de entregar la presente obra, disponible en forma impresa y en disquete, como un primer resultado de la iniciativa de ambas instituciones. La cobertura geográfica se limita a la América Tropical; esto es, desde el sudeste de México hasta el norte de Argentina, abarcando de esta manera los bosques neotropicales de zonas climáticas tropicales y subtropicales. Sin embargo, la obra tiene también estudios a nivel pantropical, pero que hacen mención a los bosques neotropicales. Se han incluido referencias de libros, artículos científicos y técnicos, ponencias en reuniones, artículos en revistas no científicas, informes finales de proyectos, bibliografías y audiovisuales. El período de revisión abarca principalmente desde 1950 hasta aproximadamente mediados de 1996. En total, contiene 1292 referencias, en su mayoría correspondientes a literatura gris.

Serie Bibliotecología y Documentación. Bibliografía No. 261997. CATIE - CIFOR, Turrialba Costa Rica. 544 pág. (Incluye 1 disquete con la base de datos) 
Agricultores migratorios de Indonesia: ¿saqueadores o manejadores de los bosques? Producción de arroz y usos del bosque entre los Uma' Jalan de Kalimantán Oriental

Colfer, C.J. Pierce y Dudley, R.G.

Traducción del Estudio de Caso de Forestería Comunitaria de la FAO Serie 6: Agricultores migratoriosalternos de Indonesia: ¿saqueadores o manejadores del bosques? Producción de arroz y usos del bosque entre los Uma' Jalan de Kalimantán Oriental (1993). ( Está traducido así n el índice de autores al principio?

El estudio examina datos longitudinales de cuatro aldeas Uma' Jalan Kenyah Dayak en Kalimantán Oriental en relación con asuntos del manejo forestal. La agricultura migratoriaos cultivos alternativos, en lugar lejos de ser ignoradaos o rechazadaos por parte de los científicos y de los formuladores de las políticas, podrían servir de modelo para el desarrollo de técnicas agroforestales que son apropiadas para los bosques del trópico húmedo. Los datos son utilizados para establecer tendencias en el área talada anualmente, preferencias forestales y de suelos terrenos, productividad y restricciones agrícolas. También se analizan los impactos de los factores ambientales, sociales estructurales y tecnológicos, los desastres naturales y el aprovechamiento forestal en aspectos seleccionados de los sistemas agroforestales. Se estudian asuntos de políticas con respecto a la población, uso de la tierra, producción y tenencia.

En conclusión, las recomendaciones de políticas incluyen un mejor control de la industria maderera, reconocimiento de los reclamos de sobre ssus tierras por parte de las personas de la comunidad, incorporación del conocimiento indígena en los esfuerzos de desarrollo agroforestal, suspensión de los proyectos que aumentan la población de Kalimantán y ayuda financiera para Indonesia por parte de la comunidad de las naciones que ayudan con estos esfuerzos.

Samarinda, Indonesia, GTZ, FAO y CIFOR. 158 pág. 
Más allá de la tumba y quema: manejo de los bosques del trópico húmedo de Borneo con base en el conocimiento indígena.

\section{Colfer, C.J. Pierce con Peluso, N.L. y Chin See Chung}

Este libro, que contiene contribuciones de una variedad de autores incluyendo a los mismos moradores del bosque, describe el sistema de manejo de los recursos naturales de la gente de Uma' Jalan Kenyah de Kalimantán Oriental, Indonesia. Colfer y sus coautores buscan presentar el conocimiento de las personas de la localidad sobre susacerca de los bosques cercanosde sus alrededores y su manejo sostenible, de manera tal que los científicos entrenados puedan comprender y utilizar. A las gentepersonas y su conocimiento del bosque, se les ve como una parte integral de la biodiversidad del bosque.

La rápida pérdida y la degradación de los bosques del trópico húmedo durante los últimos años indican que las única formas de vida únicas de esas personas que viven en y de estos bosques están bajo amenaza. Los escenariosestablecimientos urbanos y agrícolas que por lo general le siguen a la tumba del bosque no conducen a la preservación del conocimiento y los cultivos que se han desarrollado a través de los siglos.

$\mathrm{Al}$ introducir las formas en que los Uma' Jalan perciben sus recursos naturales, y al concentrarse luego en su sistema agroforestal, desde este punto de vista, se explora la base de subsistencia de estos moradores del bosque. Se define el papel que desempeña el dinero en dicho sistema y se describen las opciones disponibles para que las gentepersonas sobrevivan. En el último capítulo, se discute sobre las ramificaciones de estos resultados para el manejo forestal en los trópicos, con énfasis en cómo las costumbres Uma' Jalan se podrían adaptar para preservar al menos parte del ambiente forestal para la conservación, la biodiversidad, la subsistencia mejorada para las pequeñas poblaciones y el aprovechamiento sostenible de la madera.

New York Botanical Garden Press, Nueva York. 236 pág. 
Desde la corteza hasta el corazón del árbol: asuntos de género en el manejo sostenible de los bosques. En: Memorias de la Conferencia Internacional sobre Mujeres en la Región Asia-Pacífico: Personas, Poderes y Políticas, 11 al 13 de agosto de 1997, RELC, Singapur, 178-95.

Colfer, C.J. Pierce, Wadley, R.L., Woelfel, J. y Harwell, E.

Los estudios que se discuten aquí fueron diseñados para estimar los componentes humanos previamente identificados del manejo sostenible de los bosques (MSB). Estos componentes humanos incluyen la seguridad del acceso intergeneracional a los recursos, co-gestiónmanejo de los bosques y la identificación de los participantes interesados apropiados. En la actualidad, se están probando una gran variedad de métodos para la eficiencia de costos y confiabilidad, con la esperanza de que el bienestar de las personas y sus papeles en el manejo forestal pueda ser evaluado en forma rutinaria. Algunos de los métodos que hemos utilizado para estimar los componentes humanos del MSB incluyen una técnica de distribución de tarjetas, mapeo cognoscitivo "Galileo", un formulario de la historia local, un "Método Continuumo Interactivo" (MCI) y mapeo participativo. Se evalúan brevemente estos métodos con respectotra ael entendimiento más cualitativo de los autores sobre los asuntos de género en el contexto de la investigación, con base en el trabajo de campo etnográfico a largo plazo. Este informe reporta nuestros intentos y limitacionesfracasos por integrar una perspectiva de género al proceso de evaluaciónstimación.

Departamento de Geografia de la Universidad Nacional de Singapur, Singapur.

Desde el corazón del árbol hasta la corteza en Indonesia: género y manejo sostenible de los bosques.

Colfer, C.J. Pierce, Wadley, R.L. Woelfel, J. y Harwell, E.

El CIFOR ha estado probando criterios e indicadores para el manejo sostenible de los bosques desde 1994. Los investigadores de ese proyecto han utilizado muchos métodos para probar los puntos de vista de las personas locales sobre su acceso al bosque. Están interesados en lael percepciónsentido que tienen las personas de la co-gestiónmanejo de los recursos. Los investigadores evalúan lo que encuentran mediante pruebas 
respecto a su propio entendimiento cualitativo, con base en trabajos etnográficos a largo plazo.

Utilizando la analogía de un árbol tropical, los autores documentan sus continuos intentos por evaluarestimar los asuntos de género en la medida conformeen que pertenecen le incumben al bienestar humano y al manejo sostenible de los bosques. El trabajo se basa en la suposición de que los bosque no pueden ser sosteniblemente manejados hasta que se les ponga la debida atención a las personas que habitan en esos bosques - tanto mujeres como hombres. Se encontró que se le debe prestar mayor atención a la habilidad de los investigadores por estimar la seguridad de las mujeres al acceso intergeneracional de los recursos en forma simple, rápida $\mathrm{y}$ confiable.

Women in Natural Resources 18(4): 7-14.

\section{Árboles y arbustos Australianos: especies para la rehabilitación de terrenos y plantaciónsiembra de fincas en los trópicos.}

Doran, J.C. y Turnbull, J.W. (editores)

Este libro es una revisión y ampliación extensa de una publicación de 1986 'Multipurpose Australian trees and shrubs: lesser-known species for fuelwood and agroforestry' (árboles y arbustos australianos de múltiples propósitos: especies menos conocidas para leña y la agroforestería). Tiene la intensión de ser un texto de referencia para todos aquellos involucrados con la selección y producción de árboles y arbustos en las zonas rurales de los países en vías de desarrollo y en las partes más tropicales de Australia. Se brindan descripciones de las características botánicas, ecológicas, silviculturales y de utilización de especies potenciales.

Con la continua disminución del área de bosques tropicales y terrenos forestales, y la degradación de los bosques remanentes, se necesitan fuentes alternas para los productos y servicios de estos bosques. El desarrollo de plantaciones en pequeña escala que brinden la madera y otros productos forestales está aumentando. Los pequeños propietarios, especialmente en Asia, están tomando la opción de producir árboles en sus terrenos como áreas reservadas para la conservación del bosque, siembras en franjas o con cultivos en una variedad de sistemas agroforestales. 
La búsqueda de árboles apropiados se enfoca en mejorar la productividad de aquellas especies que ya están en uso y encontrar nuevas especies para satisfacer determinadas necesidades ambientales y sociales. Australia tiene recursos genéticos ricos de plantas leñosasmaderables, muchos de los cuales están adaptados a situaciones climáticas severas y a suelos con deficiencias de nutrientes. La evaluación de los árboles australianos para satisfacer las necesidades de las gentepersonas pobres en los países en vías de desarrollo se concentró en las especies con una distribución tropical y subtropical. Las características deseables incluyen la capacidadhabilidad de suministrarbrindar productos y servicios, además de leña para combustión, adaptabilidad, fácil mantenimiento y establecimiento, yasí como tolerancia a los ambientes extremos.

Monografia de ACIAR No. 24. ACIAR, Canberra, Australia. 384 pág.

Introducción a un compendio de especies. En: J.C. Doran y Turnbull, J.W. (editores) árboles y arbustos australianos: especies para la rehabilitación de terrenos y plantación siembra de fincas en los trópicos, 89-384. (Inglés)

Doran, J.C., Turnbull, J.W. Martensz, P.N. Thomson, L.A.J. y Hall, N.

El volumen está diseñado para brindar un texto de referencia a todas aquellas personas involucrados en la selección y producción de árboles y arbustos en las zonas rurales de los países en vías de desarrollo y en las partes más tropicales de Australia. Esta introducción al compendio de especies que sigue describe los criterios utilizados para seleccionar las especies que se incluyen en el compendio.

Las especies descritas son las que un grupo de botánicos y forestales experimentados juzgó que tienen el potencial de brindar leña, forraje, postes, sombra y protecciónrefugio, cobertura superficial terrestre u otros productos e influencias deseables, así como algunas seleccionadas específicamente por su valor alimenticio para los humanos. Cada una de las 112 especies principales se ilustra con una fotografía a colores, un mapa de distribución que muestra su frecuencia natural, condiciones ecológicas, utilización, características silviculturales, pestes y enfermedades, limitaciones y especies relacionadas.

Se presenta una tabla extensa que enumera las especies descritas y resume sus características y usos más importantes. Las características 
incluidas son el ambiente (clima y suelo), los hábitos de los árboles y los usos del árbol (maderables y no maderables).

Monografia de ACIAR No. 24. ACIAR, Canberra, Australia.

\section{Desarrollo de la agricultura nómada y la amenaza de la pérdida de la biodiversidad.}

de Jong, $W$.

El área de bosques tropicales de Indonesia es la tercera más grande del mundo. Estos bosques se se atesoran por su valoran por su alta biodiversidad, resultado de la posición geográfica única del país, pero también como un recurso natural de importancia económica. A pesar de que en las tempranas décadas décadas tempranas se produjo unade acelerada explotación forestal en Indonesia y se demostróaron poca preocupación por la sostenibilidad de los recursos forestales, recientemente se puede observar un cambio hacia políticas forestales conservacionistas genuinas. Estas nuevas políticas, sin embargo, se relacionan principalmente relacionadas con el sector forestal y mucho menos con los prolongados conflictos existentes entre el eEstado y las personas que dependen de los bosques. Todavía es una creencia común que los agricultores nómadas son los responsables de cerca de la mitad de la deforestación anual de Indonesia. Para poder resolver este problema, el gobierno ha definido una serie de medidas que pretenden convertir a los agricultores nómadas en cultivadores sedentarios. En este documento, se discuten esas medidas y se comparan con nuevas perspectivas sobre la naturaleza de la dinámica de la agricultura nómada y el papel que juega el manejo forestal en este método agrícola. Los esquemas oficiales proponen únicamente algunos tipos de desarrollos de plantaciones, lo que reduce substancialmente la biodiversidad en el paisaje agrícola. Con un ejemplo de la agricultura nómada de Kalimantán Oriental, que incluye un importante componente de manejo forestal, este documento demuestra que el desarrollo de los regímenes de manejo agroforestal tienen el potencial de traer desarrollo económico a la región, mientras que se conserva la biodiversidad. 
Operaciones Forestales para la Forestería Sostenible en los Trópicos. Memorias de un Simposio organizado por la IUFRO Grupo de Temas S3.05-00: Operaciones Forestales en los Trópicos durante el XX Congreso Mundial de la IUFRO, 6 al 12 de agosto de 1995, Tampere, Finlandia.

Dykstra, D. P. (editores)

Las operaciones de cosecha y de transporte son componentes esenciales de la forestería sostenible. El reconocimiento de estos importantes factores fue consistente con el tema del XX Congreso Mundial de la IUFRO, "Cuidado del Bosque: Investigación en un Mundo Cambiante”. El Congreso se celebró en Tampere, Finlandia, en agosto de 1995. Como parte de las memorias, se facilitó un foro para la discusión sobre las nuevas técnicas para la planificacióneación, implementación y control de las operaciones forestales en formas que promuevan el manejo sostenible de los bosques tropicales.

Este volumen es el Acta del Simposio organizado por la IUFRO Grupo de Temas S3.05-00, “Operaciones Forestales en los Trópicos”. Se discute sobre un rango de tecnologías a lo largo de una serie de regiones. El documento de Migunga discute sobre la compactación de los suelos forestales en Tanzania, mientras que Cordero y Howard evalúan el uso de bueyes para las operaciones del aprovechamiento forestal en Costa Rica. Rubini Atmawidjaja trata el manejo de ecosistemas en Indonesia, para balancear las necesidades humanas y ambientales. Elias estudia los daños del aprovechamiento forestal en Kalimantán Oriental, mientras que Aulerich revisa la aplicación de sistemas de cables aéreoscontorno por parte de una compañía indonesia. Shi Mingzhang presenta los logros del manejo forestal de la Oficina Forestal Leizhou en la provincia de Quandong, al sur de China. Un estudio de caso mexicano sobre la evaluación de los daños en una patio de operacioónes de empatiado de trozas madereras es presentado por Hernández-Díaz y Delgado-Pacheco, mientras que la situación de las operaciones forestales en la Cuenca del Amazonas es revisada por Malinovski. Cedergren et al. estiman los impactos del aprovechamiento forestal selectivo en los valores silviculturales en un bosque mixto de dipterocarpáceas de Sabah.

IUFRO/CIFOR, Viena.

También está disponible como una Publicación Especial del CIFOR, 
Antecedentes históricos y marco conceptual del código modelo de la FAO para la práctica del aprovechamiento forestal. En: Investigación sobre prácticas forestales amigables con el ambiente para la sostenibilidad de los bosques tropicales: Memorias de la Reunión vía Satélite de la FAO/IUFRO celebrada en conjuntamente con el XX Congreso Mundial de la IUFRO, Tampere, Finlandia. 4 al 5 de agosto de 1995, 57-63.

Dykstra, D.P.

El Código Modelo de Prácticas de Aprovechamiento Forestal de la FAO fue publicado a principios de 1995 por la Organización de las Naciones Unidas para la Alimentación y la Agricultura como un modelo que puede ser usado por los países miembros de la FAO contemplando el desarrollo de sus propios códigos de prácticas forestales. Este documento destaca los propósitos del Código Modelo de la FAO, revisa los eventos históricos que llevaron a su preparación, y resume las bases filosóficassiológicas sobre las cuales se construyó.

IUFRO y FAO, Roma.

Sistemas de información en la forestería.

Dykstra, D. P.

La información siempre ha sido una( verificar. Preguntar a Brian Finegan de CATIE) "equipo indispensableherramienta básica" importante de los manejadoresadministradores de los bosques. El conocimiento de las especies de los árboles, la edad del rodallevantamiento, las características del crecimiento, la calidad del sitio, las clases de suelo y de terreno, los costos del aprovechamiento y los mercados de los productos han sido todos esenciales para el manejo forestal rentable durante muchas décadas. Lo que ha cambiado es la tecnología para la recolección, el análisis y la presentación de esta información, y particularmente la velocidad en que esto de hace. Los administradores forestales deben entender las implicaciones de la información y las nuevas tecnologías de información, así como la forma en que las necesidades de información afectarán tanto al personal como la estructura de sus organizaciones. Este artículo considera algunas tecnologías de información emergentes que se están 
volviendo importantes para muchas organizaciones forestales como herramientas para mejorar la planeación estratégica y táctica, así como el manejo y el control de las operaciones.

Unasylva 48 (189): 10-15.

Aprovechamiento forestal y sistema de transporte: Viejos problemas, nuevas soluciones. En: Memorias del XI Congreso Forestal Mundial, 13 al 22 de octubre de 1997, Antalya, Turkía. Vol. 3, D: funciones productivas de los bosques, 171-86.

Dykstra, D. P. y Heinrich, R.

Las operaciones del aprovechamiento y del transporte forestal estányacen en un senderocamino casi óptimo para la creación de conflictos. Por lo que,, su cuidadosa implementación no solamente es importante para la sostenibilidad de los bosques, sino que también para la continuación de la forestería como profesión. Este documento resume las recientes iniciativas para reducir los impactos ambientales y sociales asociados con el aprovechamiento y transporte forestal. Estas incluyen esfuerzos para reducir la extensión global de las operaciones de aprovechamiento forestal en los bosques naturales mediante el aumento de los rendimientos forestales; intentos por aumentar la eficiencia económica mediante una mejor planeación y control operativos y mediante una capacitación más efectiva de los trabajadores forestales; iniciativas para desarrollar sistemas de incentivos y políticas que promoverán la adopción del aprovechamiento forestal y el sistema de transporte de impacto reducido; esfuerzos para preparar lineamientos locales y regionales para prácticas forestales amigables con el ambiente; y trabajar en el desarrollo de procedimientos para evaluar la sostenibilidad de las prácticas forestales. El documento revisa también, en forma breve, una selección de avances tecnológicos recientes que prometen convertir el aprovechamiento forestal y las operaciones de transporte en actividades más efectivas económicamente así como más amigables con el ambiente.

Comité Organizador del Congreso Forestal Mundial, Ankara, Turkía. 
Promoción del manejo forestal en las zonas del bosque húmedo del troópicalo húmedo del áfrica Ooccidental y Central aAnglofonasajona. 133 pág.

Dykstra, D. P., Kowero, G. S., Ofosu-Asiedu, A. y Kio, P.

Este proyecto financiado por el PNUMAPNUE y puesto en marcha por el CIFOR se interesó en los bosques del trópico húmedo del áfrica Occidental, más específicamente en Ghana y Nigeria, con información complementaria proveniente de Liberia, Sierra Leona y Camerún. El objetivo general era preparar una síntesis de toda la información disponible sobre las formaciones forestales húmedas del áfrica Occidental, con el fin de catalizar las iniciativas susceptibles de favorecer la adopción de principios de manejo sostenible de los bosques en toda la región.

El informe se divide en nueve capítulos. El primer capítulo describe la situación de los bosques en áfrica Occidental y Central, con un énfasis especial en la distribución de la vegetación y en los factores que influyen sobre la distribución de los bosques. Los capítulos 2 y 3 describen las técnicas pasadas y actuales de silvicultura y de manejo forestal, así como los sistemas de control del manejo. Los aspectos relativos a la biodiversidad, y el papel que desempeñan los productos no maderables del bosque, se examinan en el capítulo 4 . Las relaciones entre generaciones, los factores socioeconómicos que influyen sobre el manejo de los bosques y los asuntos de políticas y de legislación son tratados en los capítulos 5 , 6 y 7 . El capítulo 8 esboza las estrategias y las iniciativas que podrían ser adoptadas para promover un manejo sostenible de los bosques. El informe concluye con sugerencias de investigaciones que podrían ser desarrolladas para satisfacer las lagunas de conocimientos que se detectaron durante el transcurso de este proyecto.

Gracias a los fondos públicos franceses, el CIFOR y el CIRAD conducen un proyecto análogo sobre los bosques del trópico húmedo de Costa de Marfil, de Camerún, de la República Centroafricana, de la República Popular del Congo y de Gabón.

El informe está disponible en inglés y en francés.

ISBN 979-8764-09-9 (Inglés)

ISBN 979-8764-14-5 (Francés) 
Respuesta del aprovechamiento de rodales delos bosques tropicales a las operaciones de silvicultura. En: Memorias del XI Congreso Forestal Mundial, Antalya, 13 al 22 de octubre de 1997. Volumen 3, 118-22.

Favrichon, V., Dupuy, B., Maitre, H. F., Nguyen-The, N., Damio, T., Doumbia, N., Kadir, K., Petrucci, Y. y Sist, P.

El Programa de Investigación Forestal del CIRAD sobre las dinámicas de los bosques del trópico húmedo ha estado en operación desde 1974 en colaboración con diversos institutos nacionales de investigación forestal. Las investigaciones se desarrollan en una red de parcelas experimentales, de las cuales las más importantes están en áfrica (Mopri, Irobo y La Téné en Costa de Marfil y M’baiki en la República Centroafricana), América del Sur (ZF2 en Manaus, Brasil, y Paracou en la Guyana Francesa) y Asia (Strek en Berau, Indonesia). Estas parcelas han sido diseñadas con una metodología común y a las mismas se les da un constante seguimiento. Permiten estudiar las dinámicas de los ecosistemas de los bosque del trópico húmedo y las respuestas de diferentes tipos de bosque a las alteraciones tales como el aprovechamiento forestal en forma comercial y el raleo sanitarioterapéutico. Se han desarrollado muchas investigaciones en estas parcelas. Algunos de los resultados obtenidos ya han conducido a la implementación de proyectos de manejo forestal a gran escala, basados en los principios del manejo sostenible (Yapo en Costa de Marfil, por ejemplo). El propósito de este artículo es presentar una revisión de estas parcelas y delinear las tendencias de las principales respuestas de los rodales delevantamientos de los bosques a las intervenciones silviculturales. En la primera parte, se dan los parámetros del bosque natural promedio (en términos de tasa de crecimiento, expansión y mortalidad). Al mostrar la forma en que cambian estos parámetros con el tiempo, después de intervenciones silviculturales, se puede evaluarestimar el efecto de la densidad del rodallevantamiento sobre la productividad y la influencia del aprovechamiento forestal y el raleo sobre la tasa de recuperación del rodallevantamiento forestal.

Comité Organizador del Congreso Forestal Mundial, Ankara, Turkía. 
Mapeo de la distribución potencial de las plantas y los animales para el manejo de la vida silvestre: uso del paquete de computación DOMAIN. En: Romimoharto, K., Hartono, S. y Sonarno, S.M. (editores). Memorias del seminario nacional sobre el Papel de la Conservación de la Vida Silvestre y de su Ecosistema en el Desarrollo Nacional, 114-19 + dos mapas.

Gillison, A.N.

El adecuado conocimiento de la distribución y desempeño de las especies es fundamental para un manejo efectivo de la vida silvestre. En la mayoría de los casos, donde la distribuciones conocidas son muy limitadas, puede que se necesiten otros medios para obtener la información para modelar la distribución potencial de especies de importancia para el manejo. Este documento revisa brevemente algunos de los paquetes de computación disponibles incluyendo la reciente versión del DOMAIN en ambiente 'Windows' desarrollada en el CIFOR. A diferencia de otros paquetes potenciales de mapeo, el programa DOMAIN puede trabajar en forma eficiente con relativamente pocos puntos conocidos de distribución conocidos en forma relativa. Estos se correlacionan con los valores de otras variables ambientales, espacialmente referenciadas, tales como altitudelevación, suelos, tipos de vegetación y clima, que se considera que influyen en la distribución de las especies.

Entonces, un sobre de hábitathabitat conjunto de hábitat o dominio ambiental se computariza con base en estas correlaciones. El algoritmo relaciona entonces relacionacoincide con la plantilla conque contiene los valores ambientales conocidos para todos los pixeles en el área bajo estudio y mapea las clases de similitud. De esta forma, se puede hacer una valoración rápida de la distribución potencial de una o más especies, para cualquier área donde haya datos ambientales importantes disponibles y espacialmente referenciados. Un estudio de caso de Sumatra Central demuestra la forma como se puede utilizar el método para generar mapas sobre la diversidad o la riqueza de las especies de plantas.

The Indonesian Wildlife Fund (IWF), Jakarta, Indonesia. 
Conjunto de atributos funcionales de las plantas y gramática para la descripción y el análisis dinámicos de la vegetación dinámica.

Gillison, A.N. y Carpenter, G.

Los métodos convencionales de descripción de la vegetación raramente transmiten información sobre las conductas así como información con base en las respuestas, necesarias para describir efectivamente la vegetación mundial con fines de conservación y manejo. La información requerida para estos fines puede ser generada a partir de un conjunto genérico de atributos funcionales de las plantas (AFP), como se describe en este documento.

La gramática provee una base de reglas sintácticas para generar y comparar individuos como un modelo funcional o modi con basadose en combinaciones específicas de AFP. El método facilita una valoración rápida y uniforme de la respuesta de las plantas a la variación en el ambiente físico a diferentes escalas espaciales diferenciadas de las especies en forma independientemente de las especies. Esto se ilustra por medio de estudios de caso locales, regionales y globales.

Functional Ecology 11: 775-83.

\begin{abstract}
Abastecimiento de nitrógeno de los suelos y de los insectos durante el crecimiento de las "plantas jarrón" (llamadas así por su forma similar a un jarrón) Nepenthes mirabilis, Cephalotus follicularis y Darlingtonia california.
\end{abstract}

Gillison, A.N., Schulze, W., Schulze, E.D. y Pate J.S.

Este estudio investigó la adquisición de nitrógeno $(\mathrm{N})$ del suelo y de la captura de insectos durante el crecimiento de tres especies de "plantas jarrón": Nepenthes mirabilis, Cephalotus follicularis y Darlingtonia californica. Para estimar las contribuciones proporcionales de los insectos a los contenidos de $\mathrm{N}$ de las hojas y de las plantas completas, se usaron las relaciones ${ }^{15} \mathrm{~N} /{ }^{14} \mathrm{~N}$ de abundancia natural $\left(\mathrm{d}^{15} \mathrm{~N}\right)$ de plantas y "plantas jarrón" de diferentes edades, plantas no insectívoras de referencia, e insectos atrapados. Las hojas jóvenes de Nepenthes (phyllodes) que transportan "plantas jarrón" cerradas contenían los principales sumideros de $\mathrm{N}$ y se desarrollaron principalmente a partir de $\mathrm{N}$ de insectos capturados 
en algún otro lugar de la planta. Sus valores $\mathrm{d}^{15} \mathrm{~N}$ superiores en hasta un $7,2 \%$ que el valor $\mathrm{d}^{15} \mathrm{~N}$ promedio de insectos capturados (media $15 \mathrm{~N}$ valor $=5,3 \%$ ). En hojas que transportaban "plantas jarrón" viejas que actúan como fuente de $\mathrm{N}$, el valor $\mathrm{d}^{15} \mathrm{~N}$ disminuyó a 3,0\% indicando, sea una creciente contribución del $\mathrm{N}$ del suelo a aquellas partes de las plantas que de hecho capturaron los insectos o $\mathrm{N}$ obtenido a partir de la fijación de $\mathrm{N}^{2}$ por los microorganismos que podrían existir en las "plantas jarrón" viejas. El valor $\mathrm{d}^{15} \mathrm{~N}$ de $\mathrm{N}$ en el agua recolectada de las "plantas jarrón" viejas fue de 1,2\% y contenía aminoácidos libres. La fracción de $\mathrm{N}$ de insectos en "plantas jarrón" jóvenes y viejas y sus hojas asociadas disminuyó de 1,0 a $0,3 \mathrm{mg} \mathrm{g}^{-1}$. Esta fracción de insectos disminuyó aún más con el tamaño del retoño investigado. Las "plantas jarrón" contenían en promedio $61,5 \pm 7,6 \%$ (media $+\mathrm{SD}$, rango $50-71 \%$ ) de $\mathrm{N}$ de insectos, con base en el contenido de $\mathrm{N}$ de un retoño completo. Dada la ausencia de plantas no insectívoras de referencia apropiadas para Cephalotus, los valores $\mathrm{d}^{15} \mathrm{~N}$ fueron evaluados a través de una secuencia experimental desde plantas jóvenes que no tenían "plantas jarrón" hasta adultos grandes con hasta 38 "plantas jarrón". Los datos mostraron una dependencia del $\mathrm{N}$ del suelo hasta que 4 "plantas jarrón" se hubieran abierto. A partir de esa fase, el tamaño de las plantas aumentó con la cantidad de "plantas jarrón" cazadoras, pero la fracción de $\mathrm{N}$ del suelo permaneció alta. Se estimó que las plantas Cephalotus grandes derivaban $26 \pm 5,9 \%$ (media \pm SD de las tres plantas más grandes, rango $19-30 \%$ ) del $\mathrm{N}$ de insectos. En Cephalotus, observamos un valor $\mathrm{d}^{15} \mathrm{~N}$ aumentado en sumideros versus "plantas jarrón" fuente de cerca de 1,2\% en promedio. Las "plantas jarrón" fuente y de sumidero de Darlingtonia tenían un valor d $\mathrm{d}^{15} \mathrm{~N}$ similar, pero el $\mathrm{N}$ de las plantas en estas especies mostró señales d ${ }^{15} \mathrm{~N}$ más cercanas a las de los insectos que contribuyeron 76,4 \pm 8.4\% (rango 57-90\%) al contenido total de $\mathrm{N}$ de "plantas jarrón". Los datos sugirieron patrones complejos de partición de $\mathrm{N}$ de insectos y derivado del suelo entre la fuente y las regiones de sumidero en "plantas jarrón" y posiblemente una mayor dependencia en el $\mathrm{N}$ de los insectos que lo que se ha registrado en cualquier otro lugar para las especies Drosera.

Oecologia 112: 464-71. 
Opciones para el fortalecimiento del régimen legal internacionjalo para los bosques. Informe preparado para la Comisión Europea bajo el contrato de estudio B78110/96/000221/D4.

Gluck, P., Tarasofsky, R., Byron, N. y Tikkanen, I.

Las propuestas para una Convención Global de los Bosques de Acatamiento Obligatorio debatidas y rechazadas durante la Cumbre de la Tierra UNCED de 1992, en Río de Janeiro, se retoman periódicamente en foros internacionales. El caso para las acciones globales de concertación descansa sobre la existencia de los 'problemas internacionales', donde este es el único remedio efectivo, puesto que las convenciones son innecesarias e inapropiadas para los problemas nacionales. Los valores globales de los bosques son la diversidad biológica y como sumidero de carbóònsu uso como fuente de carbón. También existe una amplia preocupación internacional sobre la tala y degradación de los bosques que dañan la vida y las culturas de losas aphabitantesersonas de los bosques, así como la pérdida del conocimiento tradicional acerca de la flora y la fauna.

Este informe afirma que muchas de las preocupaciones expresadas acerca de los bosques tienen orígenes y consecuencias locales o nacionales. Las políticas nacionales y sectoriales han fomentado la conversión de los bosques hacia usos alternativos, y algunas políticas forestales han fomentado el sobre aprovechamiento forestal. Por lo general, la tenencia de los terrenos forestales todavía no está clara o está bajo reclamo, y con frecuencia los bosques han sido minados como una fuente rápida de capital, y luego son abandonados o entregados a colonizadores agrícolas o se convierten en fincas de plantaciones.

La mayoría de los aspectos 'globales' de la agenda forestal de los bosques ya han sido tratados en otras convenciones de la UNCED. Puede que sea más fácil y más efectivo mejorar la eficiencia de los acuerdos existentes y la colaboración voluntaria. Los instrumentos legales, económicos y políticos actuales pueden tratar estos asuntos. El informe examina la viabilidad, la probabilidad y los costos de alcanzar un acuerdo sobre un nuevo instrumento y luego implementar ese acuerdo; y los probables impactos distributivoscionales, tanto dentro de los países como entre ellos. 
Una convención, aunque no sea esencial, podría consolidar los fragmentos existentes de leyes internacionales relacionadas con los bosques y proveer un foro para el análisis y la convergencia de opiniones. $\mathrm{O}$, podría ser una excusa para evitar acciones más efectivas.

European Forest Institute, Joensuu, Finlandia. 78 pág.

\section{Antropología del clima en el mundo hispanoamericano.}

Goloubinoff, M., Katz, E. y Lammel, A. (editores)

La relación entre el hombre y el clima tiene una larga historia. Sin embargo ha sido poco estudiada desde el punto de vista de las ciencias humanas. Por lo regular, los factores climáticos y la relación entre el hombre y el clima se describen brevemente en los estudios etnográficos, pero a este tema se han dedicado muy pocos trabajos. La finalidad de la presente obra es ampliar, como campo de investigación, la antropología del clima, que definiremos como el estudio de la interacción entre los factores climáticos y las culturas humanas. No se trata únicamente de la acción de los factores climáticos sobre los seres humanos, sino más bien de una interacción bi-direccional, ya que la influencia de las actividades humanas sobre el clima no deja ya ninguna duda desde el punto de vista de las ciencias exactas. En efecto, el enfoque antropológico es el que predomina en este libro. La antropología no puede, sin embargo, abordar este tema sin la coparticipación con otras disciplinas; de ahí que en esta obra hayan contribuido geógrafos, historiadores, arqueólogos, sociólogos, arquitectos, biólogos, hidrólogos y meteorólogos. Esta obra se ocupa de las relaciones entre el hombre y el clima en América Latina y en España. Inicia con artículos de orden más general que plantean preguntas teóricas y metodológicas a propósito de la antropología del clima y continúa con estudios de caso en sociedades pasadas y presentes.

Quito, Abya-Yala. Colección Biblioteca Abya-Lala No. 49. Tomo 2. 315 pág. \& 292 pág. 
Medición y captura de los valores del bosque: temasasuntos para los que toman las decisiones. En: Memorias del XI Congreso Forestal Mundial, 13 al 22 de octubre de 1997, Antalya, Turkía. Vol. 4: La contribución económica de la forestería al desarrollo sostenible, 197-207.

Gregersen, H., Lundgren, A., Kengen, S. y Byron, N.

De los bosques, se derivan importantes beneficios. Por lo general, las decisiones relacionadas con la producción de los beneficios de los bosques, se toman a nivel local o, a lo sumo, a nivel nacional (por parte de los gobiernos nacionales). Sin embargo, muchos de los beneficios son globales y quedan por fuera del contexto de las decisiones locales o nacionales. Son lo que los economistas llaman "externalidades" para los que toman las decisiones. Se discuten los aspectos asuntos relacionados con la captura de los valores de los bosques o la "internalización de las externalidades". En un contexto político, surge el asunto de la "captura" o de quién paga o quién gana: ¿Qué mecanismos se pueden desarrollar para asegurar que los que toman las decisiones capturen el valor de las externalidades positivas y que se les haga pagar por las negativas que crean? Si esto no ocurre, entonces es muy probable que no las tomen en cuenta consideren en las decisiones. Se hacebrinda un resumen sobre cómo se pueden estimar y valorar los diversos valores de los bosques. La parte final del documento discute el asunto de la presentación de la información sobre los valores de los bosques a los que toman las decisiones, con un enfoque particular en los asuntos relacionados con el desarrollo de un sistema efectivo de contabilidad ambiental para los bosques.

Comité Organizador del Congreso Forestal Mundial, Antalya, Turkía.

Regeneración forestal en caminos abandonados de aprovechamiento forestal en las tierras bajas de Costa Rica.

Guariguata, M.R. y Dupuy, J.M.

Este estudio caracteriza la regeneración de plantas en cuatro caminos utilizados anteriormente para el aprovechamiento forestal (de 700 a 1.000 metros de largo) en bosques selectivamente aprovechados en las tierras bajas de Costa Rica, de 12 y 17 años después de su abandono. Se 
establecieron conjuntos de parcelas de $4 \mathrm{~m} 2$ a intervalos de 20 metros en tres micro-hábitats distintos: las huellas del camino, (donde la capa vegetal ha sido eliminada), los bordes del camino (donde la capa vegetal removida se acumula a los lados después de la construcción del camino) y los bosques adyacentes ya aprovechados. La densidad de los tallos de más de 1 metro de alto y por lo menos $5 \mathrm{~cm}$ dap (incluyendo árboles del dosel de los árboles, árboles de pisos medios, lianas, palmas, arbustos y árboles de especies de helechos) era superior en las parcelas de los bordes del camino que en las parcelas de las huellas del camino o en las parcelas de los bosques ya aprovechados. Se presume que este 'efecto de los bordes' se podría deber a la germinación de semillas enterradas de árboles y arbustos que requieren de luz, después de alteraciones moderadas del suelo, menos compactación y una mayor fertilidad del subsuelo que la de las huellas del camino. En las parcelas de las huellas de todos los caminos, la riqueza de las especies fue la menor, pero la dominancia relativa, la mayor: de 6 a 9 especies incluían juntas el 50\% del índice del Valor de Importancia (IVI), en contraste con los 11 a 15 y 16 a 22 especies necesarias para alcanzar el 50\% IVI en las parcelas de los bordes y de los bosques aprovechados, respectivamente. En tres de los cuatro caminos, se encontraron evidencias de compactación de suelos en las huellas, lo cual además de la baja fertilidad del subsuelo y falta inicial de propágulos en el lugar, podría explicar la más lenta recuperación de la densidad de los tallos y de la riqueza de especies, en comparación con las parcelas de los bordes y de los bosques aprovechados. Para los árbolestallos entre los 5 y $20 \mathrm{~cm}$ dap, la densidad y el área basal en las parcelas de las huellas promediaron cerca de una cuarta parte de los valores de las parcelas de los bordes y de los bosques aprovechados. Estimamos que la recuperación del área basal en las huellas de los caminos toma por lo menos 80 años para alcanzar el estatus encontrado en los bosques aprovechados, y la riqueza de especies toma aún mucho más tiempo. Sugerimos que los caminos utilizados anteriormente para el aprovechamiento forestal y que ahora están abandonados sirvaen como largos corredores de características florísticas y estructurales relativamente uniformes y duraderas que confieraen roles ecológicos particulares en los bosques aprovechados en forma selectiva.

Biotropica 29: 15-28. 
Estructura y Florística de rodalescosechas secundarioas y de viejo crecimientos viejos en las tierras bajas de Costa Rica.

Guariguata, M.R., Chazdon, R.L., Denslow J.S., Dupuy, J.M. y Anderson, $L$.

El estudio caracterizó la estructura de los rodaleslevantamientos y la composición florística de las formas de vida leñosasboscosas en tres rodaleslevantamientos secundarios de 16 a 18 años, que regeneraron después del abandono de potreros y tres rodaleslevantamientos cercanos de bosque de trópico húmedo de viejo crecimiento en las tierras bajas de Costa Rica. El área basal y la densidad de fustes los tallos de cada una de las cuatro clases de tamaño de las plantas (plántulas, brinzales, latizalesárboles jóvenes, arbustos y árboles) eran similares entre los tipos de rodaleslevantamientos, pero la densidad de las palmas adultas del dosel superiorde los árboles (individuos superiores a los $10 \mathrm{~cm}$ dap) era menor en los rodaleslevantamientos secundarios. La rápida regeneración de plantas leñosasboscosa observada, en comparación con otros estudios publicados en las tierras bajas de los neotrópicos, se le puede atribuir al uso moderado de los suelos y probablemente a la influencia de los suelos volcánicos ricos en nutrientes en el área de estudio. En general, la riqueza de especies de plantas era menor en los rodales levantamientos secundarios, pero esta diferencia era menos pronunciada en las clases de tamaños más pequeños (plántulas, brinzalesárboles jóvenes). El porcentaje promedio de similitud de todas las comparaciones en parejas de los rodaleslevantamientos mostraron que la composición florística de los brinzalesárboles jóvenes (tallos superiores a $1 \mathrm{~m}$ de altura y mayores a los $5 \mathrm{~cm}$ dap) era más parecidasimilar entre los rodaleslevantamientos secundarios y los de viejo crecimiento que para los árboles (tallos superiores a los $10 \mathrm{~cm}$ dap). Debido a que el valor potencial de los bosques secundarios en la conservación de la diversidad de las plantas leñosasboscosas parece ser mayor para las clases de los tamaños más jóvenes, sugerimos que se necesitan más estudios sobre la composición florística, en especial aquellos que tratan las dinámicas de los componentes del sotobosque, para refinar nuestra comprensión del papel que desempeña este recurso natural en el mantenimiento de la diversidad de las plantas en paisajes alterados. 
Seminario de la Asociación Indonesia de Biotecnología Agrícola (Garcinia mangostana, Parkia javanica, Nephelium lappaceum, y Artocarpus heterophyllus). . En: Moeljopawiro, S., Herman, M., Saono, S., Mariska, I., Purwantara, B. y Kasim, H. Prosiding. Seminario de la Asociación Indonesia de Biotecnología Agrícola. Surabaya, Indonesia 12 al 14 de marzo de 1997, 158 -73.

Hartati, N. S., Sudarmonowati, E., Fahdiar, A. y Siregar, U. J.

Los métodos para la electrofóresis de enzimas utilizando gel de almidón han sido bien establecidos para detectar y analizar las variaciones genéticas en las plantas. En este documento, se optimizaron las técnicas electroforéticas con el fin de obtener una buena resolución de los patrones de banda isozimáticos críticos para el análisis isozimático. Se emplearon modificaciones en los siguientes factores: composición de tampones o bloqueadores de extracción y sistemas electroforéticos de bloqueo; procedimientos para teñir las enzimas; y extracción de enzimas de diferentes tejidos de plantas. Se probaron once sistemas de enzimas de extractos de hojas, embriones o hipocotilos de manggis (Garcinia mangostana), petai (Parkia javanica), rambután (Nephelium lappaceum) y nangka (Artocarpus heterophyllus), utilizando tres tipos de fórmulas de tampones de extracción. Se probaron cinco sistemas de bloqueo electroforético, p.e., Litio, Histidina $\mathrm{pH}$ 8.0, Histidina $\mathrm{pH}$ 6.0, Citrato de morfolina y Borato de sodio. De los experimentos, se identificaron fácilmente los sistemas enzimáticos Aspartato amino transferasa (AAT), fosfatasa ácida (ACP), Peroxidasa (PER), Maleato dehidrogenasa (MDH) Isocitrato dehidrogenasa (IDH), Shikimate dehidrogenasa (SDH), y 6 fosfogluconatos dehidrogenasas (6-PGD). De los 11 sistemas de enzimas, 8 fueron detectados en manggis, 9 en nangka, 9 en petai y 8 en rambután. La mayoría de los sistemas detectados así como la mejor resolución de los patrones de banda se obtuvieron de los extractos de hojas. El sistema de bloqueo electroforético más adecuado para esas 4 especies es el Citrato de morfolina (MC). Los experimentos también detectaron considerables variaciones genéticas en esas especies que son importantes para posteriores estudios de investigación sobre diversidad genética.

Perhimpunan Bioteknologi Pertanian Indonesia. 
Cien años de cafetales. Dinámica de los agroecosistemas cafetaleros en la Mixteca (México). En: Katz, E. Simposio "Los Campesinos del Café en el Pasado y Presente de América Latina", Congreso Internacional de los Americanistas, Quito, 7 al 11 de julio de 1997.

Katz, E.

- el resumen no está disponible -

PNMB en Bulungan, Kalimantán Oriental, Indonesia. En: Mittelman, A. J., Lai, C. K., Byron, R. N. , Michon, G. y Katz, E. Estudio de la perspectiva de los productos no maderables del bosque para Asia y el Pacífico: hacia el año 2010. 39-46.

Katz, E.

Este subcapítulo examina las tendencias de los PNMB en el área designada como el Bosque de Investigaciones de Bulungan, que ha sido destinada por el gobierno de Indonesia al CIFOR con fines de investigación. El bosque de investigaciones cubre 303.000 hectáreas en el distrito de Bulungan, en Kalimantán Oriental, entre los ríos Malinau y Bahau, adyacentes al Parque Nacional Kayan-Mentarang. Los PNMB que se discuten incluyen animales y pájaros, alcanfor, gaharu (madera aromática), gutta percha, nueces illipe, damar (resina) y rattán. El artículo también despierta cuestionamientos sobre la forma en que estas tendencias y escenarios de desarrollarán en el futuro en áreas como el Bulungan.

Documento de Trabajo del Estudio sobre la perspectiva de los productos no maderables del bosque para Asia y el Pacífico, APFSOS/WP/28. FAO, División de Políticas y Planificación, Roma y Oficina Regional para Asia y el Pacífico, Bangkok.

Conferencia regional para el áfrica sobre conservación, manejo y utilización de las gomas vegetales, resinas y aceites esenciales., Nairobi, Kenia, 6 al 10 de octubre de 1997. Journal d'Agriculture Traditionnelle et de Botanique Applique 39(1): 179-81.

Katz, E.

- el resumen no está disponible - 
Ritos, representaciones y meteorología en la Tierra de la Lluvia (Mixteca, México). En: Goloubinoff, M., Katz, E. y Lammel, A. (editores)

Katz, E.

Es difícil imaginar que el clima no sea importante para los mixtecos, dado que se llaman a sí mismos "el Pueblo de la Lluvia". El elemento que más caracteriza el clima de esta región es la alternancia entre la estación de lluvia y la estación de sequía. El principal cultivo de subsistencia, el maíz, depende del temporal, ya que pocas zonas son irrigables. La espera de las primeras lluvias es una fuente de angustia. A su vez, el exceso de lluvia puede ser dañino. Para controlar este elemento tan aleatorio, se practican ritos para pedir e impedir la lluvia y se han desarrollado varios métodos de previsión del clima. Lluvia y sequía sirven de eje simbólico en prácticas cotidianas tales como la agricultura y la cocina, y en la expresión de la reproducción, de los procesos de la vida, de la fertilidad y la abundancia. Al mismo tiempo, el ciclo de la lluvia se representa como el ciclo de la vida humana. Todos los fenómenos meteorológicos son ligados a la lluvia, pero algunos pueden ser también "secos" o "de lluvia", como el viento, el remolino y el rayo. El paso de la lluvia a la sequía (y viceversa), marcado por ritos, se compara con el paso entre la vida y la muerte, entre este mundo y el otro mundo.

Antropología del clima en el mundo hispanoamericano,

Quito, Abya-Yala. Tomo 2. 99-134.

Las estrategias territoriales frente al estado: un ejemplo de apropiación del espacio en el Kouilou (El Congo). En: Bonnemaison, J., Cambrézy, L. y Quinty-Bourgeois, L. (editores). Le territoire: lien ou frontière? Identités, conflits ethniques, enjeux et recompositions sociales (Coloquio ORSTOM-Paris IV, París, 2 al 4 de octubre de 1995), París.

Katz, E. y Nguinguiri, J. C.

Bajo el régimen "marxista científico", las identidades de las etnias y de los clanes han estado unidas. Pero, como dentro de todo el viejo bloque socialista, ellas resurgen a más y mejor, a pesar de la importante mezcla de 
población que tuvo lugar en las ciudades y a lo largo de la línea de la vía férrea 16. Pero, como para los recientes conflictos políticos en Brazzaville (Dorier-Aprill, 1995), la coloración étnica de las reivindicaciones en Kouilou está, de todas formas, por manifestarse. Hemos visto que miembros de la misma etnia se pueden enfrentar, entre autóctonos e inmigrantes, para apropiarse de los recursos naturales. La etnia o el clan cumplen la función de grupo estratégico, de la misma forma que las redes de solidaridad aldeana o las asociaciones. El grupo se define en función de los intereses locales y puntuales a través de relaciones de clientelismo. Si los recursos comercializables disminuyen en una ciudad habitada al mismo tiempo por los Vili y los Téké, los conflictos se resuelven alrededor de la etnia. Si las diferencias se manifiestan por causa de las plantaciones de eucalipto, los aldeanos se apoyan en la asociación o bien argumentan con base en la tenencia de la propiedad del clan. La referencia a la tradición sirve de pretexto y varía también de acuerdo con el contexto: aquí, la creencia en la técnica, allá, la apropiación cotidiana de las tierras.

Pero, pretexto o no, la tradición vive y se adapta al cambio. Para las poblaciones de Kouilou, así como para otras sociedades (Bonnemaison, 1992; Vincent, 1995), el territorio que ellas ocupan está cargado de historia y de geosímbolos, tanto sobre el plano visible, como el invisible, y su apropiación es por virtud de las idiosincrasias tutelares. Puesto que las marcas materiales de la historia son escasas, la geografía simbólica se vuelve aún más importante que antes. Los que vienen del exterior para explotar los recursos lo pueden hacer, siempre que cumplan correctamente con el pago de las rentas frente a los gestores visibles e invisibles del territorio: pero, de todas formas, sus travesías por esos lugares son efímeras, puesto que la permanencia es de las idiosincrasias.

ORSTOM (CD ROM).

\section{Factores que determinan la baja deforestación: perspectiva desde el Amazonas de Bolivia.}

Kaimowitz, $D$.

Se analizan los factores determinantes de la baja deforestación en Bolivia, con base en la experiencia del paísboliviana y la literatura general sobre deforestación, y se extraen diseñan lecciones para otros países con baja 
deforestación. Una demanda doméstica débil por productos agrícolas y la pobre infraestructura de transporte son las principales causas de la baja deforestación. La baja demanda doméstica se relaciona con el pequeño tamaño de la población y el bajo ingreso per caápita, y la pobre infraestructura de transportes es una función de la baja capacidad de un país para invertir en infraestructura y factores políticos. La producción para la exportación juega un importante papel en la deforestación en estos contextos, y se ve influenciada por políticas tales como construcción de caminos, tasas de cambio sobrevaluadasapreciadas y subsidios para la agricultura comercial. Los factores que influyen sobre la tala, por parte de las familias pobres son menos relevantes. Los factores políticos e institucionales merecen una mayor atención de la que han recibido en la literatura previa sobre la deforestación.

Ambio 26: 537-40.

Avance de la agricultura sostenible en América Latina. En: Almeida, J. y Navarro, Z. (editores). Reconstruindo a agricultura, Ideias e ideais na perspective do dosenvolvimento rural sustentavel, 56-71. Editora de la Universidad, Universidad, Universidad Federal de Rio Grande do Sol, Porto Alegre, Brasil.

Kaimowitz, D.

Este documento examina hasta donde avanzó América Latina en la busca de una agricultura más sostenible, así como algunos factores que explican ese grado de avance. Se pretende efectuar un balance global de cuánto recorremos, cuáles son los obstáculos en el camino y hasta dónde es realista pensar que se puede llegar. Por agricultura sostenible, se entiende una agricultura que permite alimentar y vestir a toda la población con un costo razonable, que ofrece un nivel de vida aceptable para los que dependen del sector y que degrada poco la base de los recursos naturales. El documento concluyó que, en términos globales, el avance en dirección hacia una agricultura más sostenible fue mínimo. Mientras tanto, ese panorama general esconde el hecho de que se avanzó bastante en temas y lugares específicos. El documento está dividido en seis secciones. La primera analiza los cambios generales con respecto a la seguridad alimentaria de la población y loas ingresos recetas de la población rural. 
La segunda examina las tendencias generales respecto a la degradación de los recursos naturales relacionados con la agricultura. La tercera, la cuarta y la quinta analizan el avance de la agricultura sostenible respecto a las políticas de las instituciones y a la tecnología, respectivamente, y la sexta presenta algunas conclusiones finales. 
Patrones de uso de la tierra y el manejo de los recursos naturales en Centroamérica. En: Neidecker-Gonzáles, O. y Scherr, S. (editores). Desarrollo agrícola, sostenibilidad y alivio de la pobreza en América Latina: el papel de las regiones de laderas. Memorias del Taller, Tegucigalpa, Honduras 4 al 8 de diciembre de 1995, 105-124.

Kaimowitz, $D$.

Este ensayo analiza algunas tendencias en los patrones de uso de la tierra en las laderas de América Central durante los últimos quince años, para conocer porqué se han dado y cuál ha sido su impacto sobre los recursos naturales. El ensayo comienza con una discusión sobre los conceptos de intensificación y extensionismo y su relación con el manejo de recursos naturales. Describe tres casos empíricos de intensificación - el desarrollo hortícola en el altiplano de Guatemala, la expansión del café en Honduras y la adopción de la conservación de suelos en Nicaragua- seguido de dos casos de extensionismo - el abandono de potreros en Costa Rica y la extensión del uso de la tierra en el norte y oriente de El Salvador. Finalmente, con base en estos casos, deriva conclusiones generales sobre la formulación de políticas apropiadas para el manejo de los recursos naturales en las laderas.

IFPRI/IICA/DSE, Washington, D.C.

Políticas que afectan la deforestación paraor causa de la ganadería en América Central. En: de Groot, J.P. y Ruben, R. (editores). Sustainable agriculture in Central America, 56-71.

Kaimowitz, $D$.

El cambio más importante en el uso de la tierra en América Central durante los últimos 40 años ha sido la extensa conversión de los bosques a pastizales. La literatura presenta una serie de explicaciones para esta expansión. Dependiendo de cuáles factores se crea que son importantes, así diferirán los pronósticos y la recomendación de políticas para tratar el asunto. Este estudio utiliza la experiencia centroamericana para establecer algunas hipótesis sobre los factores que influyen la conversión de los bosques a pastizales, y sobre qué tan efectivas han sido o es probable que sean las políticas para tratar los problemas que surgen a raíz de la conversión. 
Las conclusiones derivadas del estudio indican que los precios de mercado para la carne y los productos lácteos, los cambios tecnológicos y las políticas que restringen los precios de la madera solamente tienen una influencia moderada o pequeña en la tasa de la tala forestal. Sin embargo, se descubrió que es muy probable que la construcción de caminos, las políticas de tenencia de la tierra y de uso de la tierra tengan un impacto significativo sobre la cantidad de bosques que se cortan para abrirle camino a los pastizales. También se recomienda restringir el crédito a la ganadería en las regiones de la frontera agrícola con alta precipitación pluvial.

Macmillan Press, Londres, Reino Unido.

\section{Cooperación forestal internacional: ¿ahora hacia adónde?} Kiekens, J. P. y Byron, R. N.

A pesar de que el diálogo forestal internacional ha mejorado significativamente desde la Cumbre de la Tierra, todavía queda mucho por hacer si se va a implementar el manejo forestal sostenible a escala global. Este artículo discute las tendencias actuales: frecuentes y largas conversaciones con acciones limitadas; disminución rechazo dde la asistencia oficial para el desarrollo depara hacia la actividad forestal forestería; un marco institucional internacional incompleto e incoherente; y una confianza creciente en mecanismos hipotéticos con base en el mercado, como la certificación. Concluye que la mayoría del progreso hacia la sostenibilidad forestal a nivel mundial dependerá de la buena gobernabilidad a nivel nacional e internacional. Los países deben diseñar e implementar políticas para tratar las causas subyacentes de la degradación y la pérdida de bosques forestal, tanto dentro como fuera del sector forestal. Se le debe dar forma a un marco internacional que realmente nos conduzca hacia la forestería sostenible mediante reformas de largo alcance, tales como el fortalecimiento de la asistencia para el desarrollo forestal de la forestería, la adopción de medios operacionalestivos de cooperación forestal internacional, la reforma de las instituciones forestales internacionales y la adopción de un marco legal de apoyo. 
Certificación ecológica de productos forestales: los retos económicos.

Kiker, C. F. y Putz, F. E.

Con las crecientes tasas de destrucción la disminución de los bosques en todo el mundo, ha surgido, cada vez más, la pregunta respecto a si los mercados podrían jugar un papel en la mitigación de los nocivos impactos ambientales y sociales de las actividades forestales. El Consejo de Manejo Forestal (FSC) y otros han propuesto sistemas de certificación ecológica donde, por el contrario, productos que, en general, son muy similares, son vistos por los consumidores como productos diferentes puesto que les ha brindado información adicional sobre la historia de los productos. La certificación le garantiza a los consumidores que los productos han sido producidos mediante prácticas que cumplen con estándares ecológicos y sociales fundamentales. Para que los sistemas de certificación ecológica sean viables y le entreguen productos al mercado a largo plazo, las relaciones entre los componentes clave deben evolucionar en forma económica e institucional. El sistema de certificación ecológica, compuesto por firmas locales de manejo forestal, organizaciones no gubernamentales locales de certificación, organizaciones no gubernamentales internacionales, y mercados de la madera y de productos, va más allátrasciende de los bosques y las comunidades locales hacia los mercados internacionales. Conceptualmente, el sistema es una serie de relaciones agente-principal. Este documento, además de desarrollar el concepto de la certificación ecológica, analiza las relaciones entre los muchos actores y las relaciones entre los actores y los bosques.

Ecological Economics, 1997, 20: 37-51.

\section{Evaluación de la capacidad de investigación forestal en áfrica Oriental y Meridional.}

Kowero, G.S. y Spilsbury, M.J.

Se diseña y aplica una metodología para evaluar la capacidad de la investigación a 19 instituciones en 10 países. Los indicadores utilizados no son comprehensivos, sino que son útiles para evaluar el desempeño de la capacidad de investigación actual. Los resultados vuelven a enfatizar 
sobre la necesidad de darle prioridad a la selección, el entrenamiento y el desarrollo de la mano de obra, puesto que únicamente cerca de la mitad de todos los científicos en las instituciones investigadas tienen suficiente entrenamiento y exposición a la investigación. La gerenciaEl manejo de la investigación es otro área que requiere de atención inmediata. Cerca del $17 \%$ de las instituciones investigadas destinan más del $20 \%$ de sus presupuestos de investigación a la transferencia y diseminación de los resultados de la investigación a los 'grupos de usuarios' y cerca del 28\% del tiempo de su personal se dice que estará destinado a este propósito. Esto deriva algunas preguntas sobre la maneraforma en que se formulan las prioridades y los programas de investigación y sobre la importancia de la investigación desarrollada. Existe una interacción considerable entre las instituciones en la región, pero aún no está clara la forma en que esto se puede traducir en actividades coordinadas de colaboración.

Journal of World Resource Management 8: 159-82.

Efectos de la Economía y las Políticas Sociales en los Sistemas de Manejo de la Producción - Un Estudio de Caso de las Industrias Chinas de Bambú.

Maogong, Z., Maoyi, F., Belcher, B. y Ruiz-Pérez, M.

Durante los últimos años, ha existido un rápido desarrollo de la industria de bambú en China, desde las reformass y la liberalización, las cuales han originado una serie de políticas y regulaciones económicas favorables para el desarrollo económico. Entre 1981 y 1993, el área cubierta de bosques de bambú se expandió a una tasa mayor que la tasa de crecimiento de las áreas cubiertas de bosques del país durante el mismo período. Para 1996, el valor de la producción anual de productos primarios a partir de los recursos de bambú alcanzó 0,9 billones de Dólares de los Estados Unidos de América (US\$). El valor de las exportaciones de los productos manufacturados de bambú fue de US\$ 35 millones, en 1995. Debido a que el 93\% de los bosques de bambú en las zonas rurales son de propiedad colectiva y son manejados directamente por los finqueros, el aumento en los rendimientos y las ganancias de los productos de los bosques de bambú, mejora en forma significativa los ingresos y los estándares de vida de laos habitantes personas rurales. Por lo tanto, la industria del bambú se 
ha convertido en un medio importante para reducir la pobreza entre la población rural.

El propósito de este estudio es promover las industrias de bambú en el condado de Anji, en la provincia de Zhejian. La revisión analiza los fundamentos, los enfoques y las debilidades potenciales de la industria y explora la dirección y los métodos para su posterior desarrollo.

Forestry Economics, Vol. 3 No. 1, 1998:22-43. (Inglés)

Forestry Economics No. 5, Dic., 1997:50-58.

\section{¿Necesitan las plantas pasaporte? Un estudio socioeconómico del papel que desempeñan el árbol exótico y otras especies de plantas en la provincia Quang Tri, Vietnam.}

Midgley, S.J., Byron, R.N., Chandler, F.C., Ha Huy Thinh, Tran Vo Hung Son y Hoang Hong Hanh

Un equipo mutidisciplinario evaluó el papel que desempeñan los árboles exóticos e indígenas y su uso en los sistemas de subsistencia doméstica en cuatro aldeas, típicas de tres ecosistemas claramente diferentes en la provincia de Quang Tri, en elal centro de Vietnam. Mientras que, en cada caso, los finqueros utilizaron una gran variedad de árboles y de plantas para satisfacer su subsistencia y sus necesidades de efectivo, este estudio revela la contribución crucial de los árboles exóticos. Donde la tenencia de la tierra es clara y la propiedad de los árboles no es ambigua, había un enorme entusiasmo por sembrar árboles en las cuatro áreas estudiadas.

El uso de casuarinas en las áreas de las dunas de arena, como franja protectora costera, como rompevientos de las fincas y en la agroforestería, parece tenerser efectos completamente positivos con respecto a en todos los criterios sociales, ecológicos y económicos. Asimismo, el uso de acacias brindó beneficios económicos y ambientales importantes, como rompevientos esenciales alrededor de plantaciones (exóticas) de café y de pimienta chile en los terrenos altos cerca de la frontera de Laos, y en plantaciones mixtas en fincas en los cerros bajos como componentes de un mosaico del paisaje. El cultivo de eucalipto en pequeña escala para obtención de leña y materiales de construcción locales al pie de las montañas no tiene efectos dañinos sociales o ecológicos discernibles, ofrece una de las pocas opciones económicamente viables para el uso de la tierra, tanto para mujeres como para hombres, y crea una alternativa de 
bajo costo a lapara la recolección de madera de los pocos bosques naturales que quedan.

Mediante consultas entre los aldeanos locales, los trabajadores gubernamentales de extensión forestal, los programas de asistencia de las ONG, y a través de otros usuarios de la tierra, se desarrollan sistemas silviculturales y de especies apropiados de especies y silviculturales para aumentar significativamente el bienestar social y económico con el mínimo impacto ambiental adverso. Los finqueros concluyeron que siempre que a pesar de que los árboles satisfagancen sus necesidades, no les importa el país de origen de esa especie.

CSIRO Forestry and Forest Products Technical Report No. 106. CSIRO, Canberra, Australia. 75 pág.

\section{Estudio de la perspectiva de los productos no maderables del bosque para Asia y el Pacífico: hacia el año 2010.}

Mittelman, A.J., Lai, C.K. Byron, N, Michon, G. y Katz, E.

La 'principalgranprincipal importancia de los productos forestales menores' ha sido cada vez más reconocida conforme la información acerca de la utilización, el comercio y el manejo de los PNMB ha aumentado. Este estudio brinda una perspectiva del significado de los PNMB en la región Asia-Pacífico, las tendencias actuales y las que probablemente serán las futuras en cuanto a la disponibilidad y el manejo de productos, la importancia de los PNMB para las gente personas y la economía, y los esfuerzos para alcanzar el manejo sostenible de los bosques en la región.

Los datos sobre los PNMB son escasos, por lo general contradictoriosflictivos y poco confiables, aún para las principales especies comerciales como el rattán, el bambú y los árboles de resina. Todavía los PNMB brindan productos de subsistencia importantes y empleo para quizás cientos de millones de personas en la región. Muchos de estos productos se intercambian en forma comercial, pero los residentes de las zonas de los bosques son los más dependientes de los PNMB para usos de subsistencia, tales como alimento, especiaes, aceites comestibles, medicinas, pastos, forraje, camas de paja para establos, abono orgánico, material de construcción, utensilios domésticos, fibras, ornamentación y rituales.

Es muy probable que laos 'prospección'tos' biológicaos y el creciente 
uso de las medicinas y los cosméticos naturales expandaen el comercio internacional deen estos productos. El valor de la cosecha sostenible de los PNMB podría exceder el valor derivado del aprovechamiento forestal. También existe una creciente demanda de plantas y animales en vías de extinción que se compran como trofeos y medicinas por parte de una cantidad cada vez mayor de consumidores pudeientes enafluentes de la región. Los impactos ecológicos adversos sobre los bosques del sobreaprovechamiento de especies específicas podría perturbar las interrelaciones de las especies que son vitales para mantener la integridad y la estabilidad del ecosistema.

Mucho de nuestro conocimiento sobre el manejo sostenible de PNMB se deriva del conocimiento técnico indígena, el resultado de siglos de experimentación por parte de loas habitaentespersonas tradicionales e indígenas. Hasta hace poco, básicamente esto se ignoraba. Los rápidos cambios sociales, culturales y económicos asociados con la modernización tienen un efecto profundo en losa habitaentespersonas $t$ tradicionales del bosque. La tendencia global es hacia la disminución de los recursos de los PNMB. Las organizaciones que luchan por unade comercialización justa podrían convertirse en importantes mecanismos en el futuro, para asegurar que los recolectores y los procesadores reciban un precio equitativojusto por los productos que son manejados y cosechados en forma sostenible.

Oficina Regional de la FAO para Asia y el Pacífico, Bangkok, Tailandia. 65 pág.

\section{Las poblaciones de Okoumés en Gabón. Su dinámica y crecimiento en las zonas costeras.}

Nasi $R$.

La mediciónda y el seguimiento anual, entre 1987 y 1994, de 34 parcelas de edad conocida (que representan 22 hectáreas y casi 14.000 árboles) establecidas en las poblaciones de Okoumés de la zona costera de Gabón, permiten precisar la dinámica de sus formaciones vegetales pauci específicas. Sus poblaciones son el resultado de la colonización a velocidades variables de las sabanas o de roturaciones para cultivosdesfases culturales en ausencia de fuegoincendios. Su composición florística varía con la edad, pero todas presentan un fondo 
florístico común de una decena de especies que constituyen más del 90\% de los individuos censados. El área basalLa superficie terrestre aumenta y la densidad disminuye con la edad, para estabilizarse alrededor de valores «límites» cerca de los 40-45 años. La mortalidad, muy fuerte en las parcelas jóvenes, disminuye con la edad. Afecta esencialmente los árbolesvestigios débiles de diámetro menor pertenecientes al estrato estado dominado. La muerte de los dominantes de mayor edad constituye un fenómeno raro ( $1 \%$ de las muertes y $0,006 \%$ del conjunto de árboles tallos) aún para las parcelas de 60 años de edad. Las medidas de crecimiento en circunferencia y área basalsuperficie terrestre muestran que lo esencial del crecimiento se producees el hecho de que en la población de Okoumés son dominantes. En función de los valores de crecimiento obtenidos, hace falta cerca de 75 años para producir un Okoumé «promedio» explotable de $70 \mathrm{~cm}$ de diámetro dentro de las condiciones de Oyane. Los resultados se compararon con los obtenidos en las formaciones vegetales similares al centro de Gabón por el proyecto ECOFAC.

Bois et Forêts des Tropiques, no. 251,1997. Pág. 5-26.

Mercados de los productos forestales no maderables del bosque en la zona de los bosques húmedos de Camerún. En: Doolan, S. (editor). African rainforests and the conservation of biodiversity. Memorias de la Conferencia Limbe, 17 al 24 de enero de 1997, 128-33.

Ndoye, O. y Ruiz-Pérez, $M$.

Muchos de los habitantes rurales dependen de los productos no maderables del bosque (PNMB) para su subsistencia y sus necesidades de ingresos. Las crecientes urbanizacioónes (como resultado de las migraciones rurales hacia las zonas urbanas) esson un factor importante que expande el tamaño del mercado local de los PNMB. Este documento se enfoca en los mercados locales en las zonas de bosque húmedo de Camerún y en los comercializadores intermediarios que facilitan la coordinación (o el encuentro pareo) de la oferta y la demanda de PNMB mediante el suministro de puntos de salida al mercado la facilitación de puestos de venta para los finqueros y garantizando una fuente de abastecimiento doméstico de PNMB para los consumidores. No siempre se conocen las 
restricciones de conducta y los procedimientos operativos comunesestándares de los intermediarios del mercado, en especial al inicio de lasla crisis económicas. Los comerciantes de PNMB no siempre tratan con un sólo PNMB. Esta estrategia les ayuda a subsidiar en forma cruzada a los diferentes PNMB. Lo que significa que el margen obtenido por vender un PNMB en particular puede ser utilizado para subsidiar otros PNMB (compras, almacenamiento, procesamiento). La cantidad de PNMB comercializados en las zonas de bosque húmedo de Camerún es importante. Adicionalmente, los márgenes de comercialización obtenidos por los comerciantes varía entre un $16 \%$ (para Dacryodes edulis) y un $30,4 \%$ (para Irvingia gabonensis) del valor de las ventas. Además, los márgenes de comercialización recibidos por los que comercializan Dacryodes edulis, Ricinodendron heudelotii e Irvingia gabonensis fueron superiores al salario mínimo en la mayoría de los mercados. Por lo tanto, el estudio confirma el papel que desempeñan los PNMB como fuente de empleo y de ingresos para los comerciantes y sugiere la necesidad de desarrollar estos mercados.

Unión Europea/Proyecto Monte Camerún /DfID/EARTHWATCH, Londres.

Mercados de los productos forestales no maderables del bosque en la zona de los bosques húmedos de Camerún.

Ndoye, O., Ruiz- Pérez, M. y Eyebe, A.

Muchos de los habitantes rurales en las regiones tropicales dependen de los productos no maderables del bosque (PNMB) para su subsistencia y sus necesidades de ingresos. Los mercados locales juegan un papel importante en facilitar a los hogares que dependen del bosque la obtención de una parte importante de sus ingresos de efectivo a través de la venta de PNMB. Las crecientes urbanizaciónones (como resultado de las migraciones rurales hacia las zonas urbanas) son un factor importante que expande el tamaño del mercado local de los PNMB.

Este documento se enfoca en los mercados locales y en los comercializadores intermediarios que facilitan la coordinación (o el encuentro pareo) de la oferta y la demanda de PNMB mediante el suministro de puntos de salida al mercadola facilitación de puestos de 
venta para los finqueros y garantizando una fuente de abastecimiento doméstico de PNMB para los consumidores. Presenta los resultados de un estudio que analizó los cuatro principales PNMB vendidos en la Zona de Bosque Húmedo de Camerún (Dacryodes edulis, Irvingia spp., Cola acuminata y Ricinodendron heudelotii). El estudio encontró que la cantidad de PNMB comercializados es significativa, alcanzando casi US $\$ 1,75$ millones, en la primera mitad de 1995. Más de 1.100 comerciantes, principalmente mujeres, están comprometidos con la distribución de PNMB. Adicionalmente, los márgenes de comercialización obtenidos por los comerciantes varía entre un 16\% (para Dacryodes edulis) y un 30\% (para Irvingia gabonensis) del valor de las ventas. Por lo tanto, el estudio confirma el papel que desempeñan los PNMB como fuente de empleo y de ingresos no solamente para los que recolectan, sino que también para los comerciantes y sugiere la necesidad y el potencial de desarrollar estos mercados.

ODI Documento de la Red de Forestería de Desarrollo Rural 22c.

ODI, Londres, Reino Unido 20 pág.

Beneficios no comercializables de los bosques que no se transan en el mercado: un enfoque de modelosaje para la intervención de políticas en Mozambique. En: Memorias de un Simposio Internacional sobre los Beneficios No Mercadeables de la Forestería, Edimburgo, 24 al 28 de junio de 1996.

Nhantumbo, I., Dent, J.B., Kowero, G.S. y McGregor, M.J.

Los productos forestales comerciables son normalmente el foco de atención en el manejo forestal, contrario a los productos no comerciables y los beneficios que no se transan comercializables en el mercado, tales como el control de la erosión, los valores estéticos y tradicionales de tipo ceremonialde las ceremonias estéticas y tradicionales, el mantenimiento de la biodiversidad, la conservación de la vida silvestre y otros beneficios intangibles. Eesta situación resulta del hecho de que los bienes que se transan en el mercadomercadeables están incluidos en las cuentas nacionales, en términos de su contribución al PIB. Los proxis poderes potenciales y hasta controversiales para el análisis de los impactos socioeconómicos de las variables ambientales incluyen la creación de las 
Cuentas de los Recursos Ambientales (REA) y el Producto Interno Neto Ambiental Ajustado (EDP) así como otros enfoques tales como el cambio de políticas macroeconómicas y la programación lineal.

La planificacióneación del manejo sostenible de los bosques demanda una integración de todos los recursos, incluyendo los usos potenciales por parte de diferentes grupos sociales a nivel nacional e internacional en el mediano o largo plazo. Tanto el compromiso del sector formal, como el del informal en la planificacióneación e implementación de medidas para proteger el ambiente, a nivel nacional, dependen del valor de los recursos percibido por cada asociado. Sin embargo, el método más utilizado para la valoración del ambiente Valoración Contingente (CV), todavía está enfrentado una gran cantidad de escepticismo respecto a la credibilidad de sus resultados. Por lo tanto, los problemas metodológicos surgen aún más al tratar de analizar el impacto probable de futuras políticas/estrategias ambientales alternativas a nivel macro en una situación de escasez de datos, donde los grupos meta tienen la información mínima o no la tienen sobre los bienes ambientales. Otras dificultades incluyen la derivación de coeficientes y la selección de niveles de agregación apropiados.

En esta investigación, se desarrolla un marco de un modelo de programación matemática multiobjetivo que incorpora las preferencias de los finqueros, los objetivos y las prioridades ambientales regionales y nacionales, para determinar el impacto de la utilización de los productos forestales que se transan en el mercadomercadeables en los beneficios no mercadeables de los bosques que no se compensan en los mercados. La incorporación de estos últimos en el modelo facilita la base de un poderoso sistema de apoyo a las decisiones para las intervenciones de políticas.

\section{Estimación de la vitalidad de los brinzales deárboles jóvenes para el pino de Eescocéscia (Pinus sylvestris L.) en la Karelia Rusa.}

Oreshkin, D.G., Skovsgaard, J.P. y Vanclay, J.K.

Se propone un nuevo método para estimar la vitalidad o el crecimiento potencial de los brinzales árboles jóvenes de pino de EscociaScots (Pinus sylvestris $L$.), con base en la altura, el diámetro y el incremento de la altura. Se utilizó un proceso de dos etapas para establecer el índice de vitalidad. 
Se hizo una regresión de los logaritmos de altura, de diámetro y de incremento de la altura en relación concontra la edad, para ajustar el amplio rango de edades presentes en nuestros datos (cerca de. 10.000 brinzalesárboles jóvenes con edades entre los 4 y 50 años). Luego se utilizó el análisis de componentes principales los principales componentes, para obtener coeficientes, que fueron a su veéza cambio estandarizados en cada eje, para brindar el índice de vitalidad coen base ena una escala de escalado en desviaciones estándares. Esta escala estandarizada permite que el rango de un individuo de la población sea evaluado y atrae la atención sobre hacia posibles forasteros árboles que no se ajustan a la escala (outliers). El uso de residuos ajustados a la en su edad aseguró que el estimador fuera independiente de la edad y estable a través de una amplia gama de edades. El primer componente principal indica si un brinzal árbol joven es relativamente alto (ponderación peso=0,50), gruesoespesor (ponderación $=0,5)$ o de rápido crecimiento (ponderación $=$ 0,5 ) o de rápido crecimiento para su edad (ponderación $=0,7$ ) para su edad. La mayoría de la información está contenida en el primer componente principal, pero el segundo componente, que explica cerca del $10 \%$ de la variación, parece brindar alguna utilidad como indicador de la 'aceleración' debido a las condiciones cambiantes. Las medidas resultantes de vitalidad han sido útiles para la investigación y el manejo en el bosque seco de pinos de musgo/ y líquenes en la Karelia de Rusia, pero son específicos de esta especie, localidad y ecotipo. Es necesario desarrollar más investigación y datos específicos del lugar para adaptar el sistema a otras situaciones.

Forest Ecology and Management 97: 147-53. 
Situación actual, tendencias y escenarios futuros para la conservación forestal incluyendo las áreas protegidas en la región Asia-Pacífico. Documento de Trabajo del Estudio de la perspectiva de los productos no maderables del bosque para Asia y el Pacífico Serie No. APFSOS/WP/04.

Paine, J.R., Byron, N. y Poffenberger, M.

Este documento pretende evaluar las perspectivasprospectos futuraos para la conservación forestal de, áreas especialmente protegidas, en la región Asia-Pacífico para el año 2010, bajo tres escenarios, con laos siguientes supuestososiciones:

- continuación del actual nivel de acción y ambiente de políticas ('status quo');

- campañas ambientales sostenidas y un mejor papel más destacado para la conservación más destacado del que existe en la actualidad;

- cambios negativos en las políticas y las acciones relacionadas con la conservación.

Laas comunidades localespersonas de la localidad permitirán que los bosques permanezcan si creen que la existencia continua de ellos les reporta máslos bosques es más beneficiosa (p.e., que genera mayores ingresos o que tiene valores culturales o sociales) que su eliminaremoción. De lo contrario, los bosques se talan. Puede que las políticas oficiales de conservación sean irrelevantes, o hasta directamente contradictoriaos por las políticas externas alfuera del sector forestal. Entonces, los a problemas de conservación de la biodiversidad y la deforestación sólo pueden resolverse considerando los problemas de las comunidades que dependen de los bosques en un contexto más amplio, tal como los movimientos de las poblaciones y el acceso a la tierra.

Muchos países asiáticos están en el proceso de formular políticas que faciliten la participación de las comunidades en el manejo de los bosques públicos para la de conservación. Estos nuevos enfoques de colaboración, si bien son ampliamente apoyados por las organizaciones donantes, son todavía imperfectos. únicamente un porcentaje muy pequeño de la propiedad de los bosques públicos de Asia ha sido puesto bajo cogestiónmanejo. Durante décadas, se ha visto a las comunidades como una amenaza para la biodiversidad de los bosques y la producción comercial. El atraer a las comunidades formalmente dentro del manejo y devolverles la autoridad y los derechos es un cambio drástico de dirección. El proceso 
de negociación de los acuerdos de manejo de la conservación entre las comunidades, los departamentos forestales y los gobiernos locales es formidable. Las comunidades sin poder político y las mujeres necesitan una efectiva representación conforme se formulen nuevos acuerdos de manejo forestal para la conservación.

Oficina Regional de la FAO para Asia y el Pacífico, Bangkok, Tailandia. 74 pág.

Catalización de la regeneración de bosques nativos en
tierraenos tropicales degradadasterioradosdegenerados. Parrotta, J.A., Turnbull, J.W. y Jones, N.

La tala de los bosques, la degradación forestal a través de las alteraciones causadas por el hombre de los humanos y y el deterioro de la productividad de losa suelostierra debido a prácticas agrícolas no apropiadas son un importante problema en los trópicos. La restauración de la salud y la productividad de los ecosistemas por lo general se han basado en el abandono de la tierra y su posterior sucesión naturalherencia natural. Durante los últimos años, se han considerado opciones de manejo para acelerar la recuperación y restaurar la productividad, la biodiversidad y otros valores. El uso de plantaciones de árboles para catalizar la restauración de bosques y terrenos degradados en los trópicos se trataron durante un simposio celebrado en Washington D. C., en junio de 1996. Se reportan las conclusiones y sugerencias para la investigación futura, con el fin de desarrollar opciones apropiadas de manejo. Existe una fuerte evidencia de que las plantaciones pueden facilitar las sucesióones de los bosques en sus sotobosques mediante la modificación, tanto de las condiciones físicas como biológicas del sitio. Los cambios en la luz, la temperatura y la humedad en la superficie del suelo permiten la germinación y el crecimiento de semillas transportadas hasta el sitio por la vida silvestre y otros vectores de bosques adyacentes remanentes. Son necesarios el desarrollo y el diseño de opciones de manejo para apoyarsistir en este proceso, tomando en cuenta realidades socioeconómicas, prioridades de desarrollo y metas de conservación. 
Estimación y monitoreo de los recursos forestales y los bosques. En: Memorias del XI Congreso Forestal Mundial, Antalya, 13 al 22 de octubre de 1997, Volumen 1, 17-29. Persson, R., y Janz, K.

El interés por una mejor información acerca de los recursos forestales está creciendo, tanto a nivel nacional como internacional. En la actualidad, surgen con frecuencia las demandas de nuevos tipos de información surgen frecuentemente (p.e., con respecto a la diversidad biológica, a los productos no maderables del bosque, la calidad del bosque). No obstante, la base conceptual y metodológica para satisfacer muchas de estas nuevas demandas es insuficiente. Más aún, para responder a todas esas nuevas preguntas, se requieren fondos que no estarán disponibles en el futuro previsible.

Durante las últimas décadas, se ha alcanzado mucho progreso en los métodos y las técnicas de inventarios (p.e., en los campos de los sensores remotos y los Sistemas de Información Geográfica - SIG). Sin embargo, todavía existen serias deficiencias en la información sobre los recursos forestales, tanto en los países desarrollados como en los países en vías de desarrollo. Los resultados de las valoraciones de los recursos forestales de la FAO en 1990 indican que, en los países en vías de desarrollo, únicamente un $14 \%$ de las zonas de bosques están cubiertas por inventarios de alta confiabilidadredibilidad, mientras que el $43 \%$ están cubiertas de inventarios de baja confiabilidadredibilidad. En los países desarrollados, que en este contexto en particular incluyen a los países en transición, la calidad de la información forestal varía ampliamente entre los países y existen serias brechas de información.

La Valoración de los Recursos Forestales (FRA) emprendida por la FAO utiliza dos enfoques. El que produce información a nivel del país se basa principalmente en datos nacionales. Como existen deficiencias en los datos nacionales, los resultados producidos por la FRA, naturalmente también tendrán deficiencias. La información mejorada en la FRA requiere, principalmente, de inventarios nacionales mejorados.

Las estimaciones de la FAO para 1995 muestran que cerca del 27\% del área terrestre del mundo está cubierta de "bosques". Como promedio, existen cerca de $110 \mathrm{~m} 3$ de madera por cada hectárea de "bosque". Cada año, el área de bosques en los países en vías de desarrollo se está 
reduciendo en cerca de 13 millones de hectáreas, mientras que el área de bosques en los países desarrollados está aumentando en cerca de 2 millones de hectáreas (excluyendo a Rusia).

Una nueva FRA se está llevando a cabo ahora, y será publicada en el año 2000. La situación de la información en los países ha decaído en vez de mejorar desde la anterior FRA 1990. Eln trabajo con la FRA 2000 deberá utilizarse como una herramienta para mejorar la capacidad nacional, de manera que la mayoría de los países tengan una mejor información como base para el manejo de sus propios bosques y que, como efecto secundario, puedan facilitar información de calidad para la FRA 2010. La construcción de dicha capacidad toma su tiempo. $\mathrm{Y}$ es, a nivel nacional/local, que se puede hacer el mejor uso de los inventarios forestales.

Monitoreo de los beneficios de la fijación de carbono asociados con un proyecto de aprovechamiento forestal de impacto reducido en Malasia.

Pinard, M. A. y Putz, F. E.

El Proyecto de Aprovechamiento Forestal de Impacto Reducido, un proyecto piloto de fijación de carbono, se inició en 1992, cuando una empresa eléctrica brindó fondos a un concesionario forestal para implementar lineamientos de aprovechamiento forestal en bosques de dipterocarpáceas. La razón fundamental para la fijación es que, cuando se reducen los daños del aprovechamiento forestal, se retiene más carbono en los árboles vivos, y debido a que los daños en el suelo se minimizan, la productividad de los bosques permanece alta. Para estimar el beneficio del carbono asociado con la implementación de los lineamientos de aprovechamiento forestal, se desarrolló un programa de monitoreo con base en: 1) estudios de campo para medir los inventarios y los flujos de carbono; 2) un modelo computarizado de las dinámicas del carbono forestal para simular varias combinaciones de intensidades de aprovechamiento forestal y de daños; y, 3) un modelo de proyección para calcular el balance de carbono a través de la vida del proyecto.

El 75\% del carbono almacenado en este bosque es en biomasa, y, de éste, el 59\% está en árboles grandes $(>=60 \mathrm{~cm}$ diámetro); 
consecuentemente, las estimaciones confiables de variables relacionadas con los árboles grandes son críticas para la estimación de los beneficios del carbono. Se recomienda la utilización de métodos alométricos para estimar la biomasa debajo del suelo, más que los métodos de muestreos en hoyos, dada su baja efectividad de costoscosto-efectividad en la obtención de estimaciones precisas de biomasa leñosas de las raíces. Los análisis de sensibilidad de las variables utilizadas en el modelo de simulación sugieren que el mantenimiento de la productividad del ecosistema tiene una gran influencia en el almacenamiento del carbono en los bosques a largo plazo. Las proyecciones de las diferencias de almacenamiento de carbono entre los sitios de aprovechamiento forestal de impacto reducido y los de aprovechamiento forestal convencional, se basan en los supuestos sobre la mortalidad de los árboles, el crecimiento y la selección; los datos publicados para sitios comparables en Malasia son probablemente apropiados para estimar la recuperación de los bosques de aprovechamiento forestal convencional, pero no de impacto reducido. Se espera la continuación del trabajo de campo que facilite los datos necesarios para evaluar los supuestos de los modelos.

Mitigation and Adaptation Strategies for Global Change 2: 203-215.

¿Cómo acertarle a un Blanco en Movimiento? La Sostenibilidad, las Personas y los Bosques. Documento presentado al Institut Pertanian Bogor (IPB) - Universidad de Göttingen.

Prabhu, R. y Vanclay, J. K.

La sostenibilidad en el contexto del desarrollo y el manejo de los bosques es un concepto definido por los seres humanos. Conforme cambian las necesidades humanas, a través del tiempo y del espacio, también lo harán las expectativas de cuáles beneficios y servicios de los bosques necesitan ser sostenidos. Gran parte de la investigación del CIFOR se enfoca en lograr una mejor comprensión brindar un mejor entendimiento de cuáles son los aspectos clave que controlan que dirigen ael manejo de los bosques y cómo podrían verse influenciados para brindar soluciones sostenibles. Dos enfoques complementarios para entender mejor los aspectos claves y las dinámicas del manejo de los bosques son el tema de esta presentación. 
En el primer enfoque, el CIFOR trata de identificar los asuntos clave en términos de Criterios e Indicadores para el manejo sostenible de los bosques, con el propósito de desarrollar mejores métodos de valoración. El segundo enfoque se basa en el modelaje de las interacciones de los seres humanos y los bosques. Ambos enfoques ilustran la necesidad de desarrollar herramientas que sean lo suficientemente generalizables para que sean de utilidad con una gran cantidad de personas,; pero, a la vez, suficientemente adaptables a las condiciones locales de manera que tengan utilidad práctica.

Seminario sobre la sostenibilidad de las márgenes del bosque, IPB, Bogor, Indonesia, 14 al 17 de abril de 1997. 7 pág.

Métodos de investigación para el aprovechamiento forestal de impacto reducido: resultados del taller. Informe del Seminario Internacional de Capacitación sobre Aprovechamiento Forestal de Impacto Reducido y Manejo de Bosques Naturales, 14 al 27 de julio de 1996, en Bogor y Kalimantán Oriental, Indonesia. 84 pág.

Putz, F. E. , Elias, Sist, P., Dykstra, D. P. y Heinrich, R.

En julio de 1996, con el apoyo de la FAO, la USAID y el Servicio Forestal del Departamento de Agricultura de los Estados Unidos de Norteamérica, el CIFOR ofreció su Primer Seminario Internacional de Capacitación de Investigación Internacional sobre Aprovechamiento Forestal de Impacto Reducido y Manejo de Bosques Naturales. Los participantes se seleccionaron de diez países y representaron disciplinas desde la silvicultura y la hidrología, hasta la biología de vida silvestre. Mediante el taller, se integraron ejercicios de campo con actividades de aulaclase, inicialmente, en las plantaciones forestales experimentales cerca de la sede del CIFOR, y, luego, en una concesión forestal industrial en Kalimantán Oriental. Los participantes también desarrollaron un proyecto de un día de duración sobre algún aspecto del manejo forestal. Sus informes escritos constituyen la mayor parte de esta publicación y han sido agrupados por temas. El primer grupo comprende siete documentos relacionados con la compactación del suelo y la erosión; el segundo consiste de diez documentos, uno sobre el daño ade los árboles, y los restantes sobre la densidad y el crecimiento de los árboles que ocurren en diferentes situaciones y bajo diferentes condiciones. 
Experiencias prácticas y prioridades de investigación en la silvicultura de bosques naturales en América Tropical. Actas del Seminario-Taller realizado en Pucallpa, Perú del 17 al 21 de junio de 1996.

Sabogal, C., Camacho, M. y Guariguata, M. (editores)

Esta publicación recoge las ponencias presentadas en el Seminario-Taller celebrado en Pucallpa, Perú, del 17 al 21 de junio de 1996, con el apoyo de CIFOR, CATIE e INIA, en donde se pretendió involucrar a investigadores y técnicos con experiencias directas en el campo de la silvicultura de bosques naturales en la región, y así mejorar la colaboración y potenciar la interacción entre individuos de diferentes instituciones que trabajan en este sector. Este encuentro forma parte del proceso de impulsar los conocimientos de silvicultura; investigación y experiencias, como componente crítico para el manejo sostenible de los bosques en América tropical.

Se presentaron 3 conferencias magistrales y 12 ponencias en las que se abordaron las experiencias concretas de investigación silvícola en el Caribe, en general, y en bosques del Amazonas peruano y colombiano, en particular; los diferentes tratamientos silviculturales, impactos y efectos del aprovechamiento forestal de plantaciones en áreas específicas de Costa Rica, Perú y Guatemala, y el aprovechamiento de productos no maderables del bosque con fines de producción diversificada.

Publicación Especial CIFOR/CATIE/INIA

Turrialba, Costa Rica. 236 pág.

Tecnologías para el manejo sostenible de los bosques: retos para el Siglo 21.

Sayer, J.A., Vanclay, J.K. y Byron, N.

La tecnología ayudará a tratar los retos de la forestería sostenible en el Siglo 21. Algunos de esos retos incluirán el cambio de la producción de los bosques nativos hacia las plantaciones en áreas de ventajas comparativas, procesos más eficientes que desvinculan de desenlace de los productos de uso finales de las al usuario con características de la la materia prima madera en bruto bruta, demanda creciente, mejores tecnologías de información para apoyar a los que toman las decisiones y 
más opciones para conservar la biodiversidad. Las definiciones sobre sostenibilidad variarán en el tiempo y el espacio, conforme cambien las expectativas y las aspiraciones de la sociedad, por lo que no puede existir una 'bala de plata' que garantice la sostenibilidad. No obstante, el progreso se puede facilitar con un enfoque sistemático del manejo forestal, que abarca que adopte el ciclo usual de la planificacióneación: formulación de objetivos, preparación de la estrategia, planificacióneación, implementación, monitoreo y evaluación. Esto requiere de una buena comprensión de cada situación particular Para esto, se requiere tener un buen entendimiento de cada situación particular. La gerencia necesita de buenos recursos para la evaluación y sistemas de apoyo para la toma de decisiones; deben fomentar la participación de los actores en la toma de decisiones, los costos y los beneficios; y asegurar los procedimientos efectivos para la resolución de los conflictos. Dentro de un sistema apropiado, los avances técnicos tales como mejores máquinas mejores y nuevos implementos podrían ayudar a marcar la diferencia, pero no podrán garantizar por sí mismos la sostenibilidad. Las tecnologías importantes para la forestería sostenible son aquellas que promueven una mejor comunicación entre los actores y permiten decisiones informadas que abarcan escalas desde el gen hasta el ecosistema. Este sigue siendo un reto importante para los manejadores de bosquesadministradores forestales en su busca por la sostenibilidad.

Commonwealth Forestry Review 76: 162-70.

\section{Políticas forestales en Centroamérica. Análisis de las restricciones para el desarrollo del sector forestal.}

\section{Segura, O., Kaimowitz, D. y Rodríguez, J. (editores)}

Este libro tiene como objetivo identificar las restricciones que impiden el desarrollo del sector forestal en forma sostenible en los sietes países del istmo centroamericano. Incluye estudios nacionales, producto de una investigación y consulta, sobre las políticas forestales de cada país, realizados por investigadores nacionales. Para cada uno de los países, describe la situación de su sector forestal, la política forestal imperante y las políticas y restricciones de otros sectores que afectan a los bosques. También presenta una síntesis regional de los estudios. 


\section{EI proyecto STREK.}

Sist, P. y Bertault, J.G.

STREK es la sigla del proyecto indonesio Técnicas Silviculturales para la Regeneración de Bbosques Ssobre-explotados en Kalimantán Oriental. El Ministerio de Forestería de Indonesia y el CIRAD-Fôret fueron las instituciones que lideraron el proyecto. La empresa maderera estatal indonesia INHUTANI I fue la agencia ejecutora en el campo. El área de estudio estuvo ubicada en la provincia indonesia de Kalimantán Oriental. La concesión INHUTANI I estaba cubierta principalmente por bosques primarios y por bosques aprovechados de dipterocarpáceas de tierras bajas. Se seleccionaron dos sitios de 1.000 hectáreas cada uno. En el primer sitio (RKL 1), aprovechado entre 1978-1979, se establecieron 6 parcelas de 4 hectáreas cada una. En el segundo sitio (RKL 4), cubierto de bosques primarios hasta 1991, se establecieron 12 parcelas de 4 hectáreas cada una. En las parcelas, se midieron, numeraron y mapearon en una escala de 1:200 todos los árboles con dap $>10 \mathrm{~cm}$. También se evaluaron, en cada parcela, otros aspectos físicos importantes, tales como la topografía y el suelo. Dos tratamientos silviculturales diferentes (raleo químico) se probaron en el RKL 1. Se aplicaron técnicas de aprovechamiento forestal de impacto reducido (AFIR) y se compararon con las convencionales en el RKL 4. Se definieron cuatro tratamientos: dos de AFIR, con dos límites de diámetro diferentes $(>50 \mathrm{y}>60 \mathrm{~cm})$, uno convencional y un control sin cosecha. Las técnicas de aprovechamiento forestal de impacto reducido incluían la planificacióneación de los caminos de arrastre antes del aprovechamiento, la tumba direccionada y la corta de lianas escaladora de los árboles tres meses antes del aprovechamiento.

FAO Forest Harvesting Bulletin 7(1): 4.

Éxito en la regeneración y el crecimiento temprano de rodaleslevantamientos forestales. Documentos seleccionados de la Conferencia de la IUFRO celebrada en Copenhague en junio de 1996.

Skovsgaard, J.P. y Vanclay, J.K. (editores)

Diez documentos seleccionados de las memorias completas de la conferencia recién mencionada, que proveen resultados de trabajos más completos sobre 
los diferentes aspectos de la regeneración y el crecimiento temprano. La conferencia discutió ampliamente sobre el tema, abarcando aspectos teóricos y aplicados, plantaciones y silvicultura 'cercana a la naturaleza', bosques naturales y de plantaciones en zonas tropicales, temperadas y boreales. Los documentos incluidos en esta edición especial de Forest Ecology and Management reflejan una amplia perspectiva, tanto sobre el enfoque de las especies como el regional.

Edición Especial de Forest Ecology and Management 97: 93-205.

Establecimiento de técnicas de marcadores genéticos bioquímicos para Shorea sp- especies forestalesde árbol del bosque tropicales de Shorea sp.

Sudarmonowati, E., Hartati, N. S. y Siregar, U. J.

Se estudiaron dos tipos de materiales, seis composiciones de tampones de extracciónaprovechamiento de amortiguación y tres sistemas de tampón de aprovechamiento electroforéticos, con el fin de establecer procedimientos óptimos para la obtención de una buena resolución de 14 sistemas de enzimas en 12 especies de Shorea, que pertenece a la familia de las Dipterocarpáceas. Se pudieron detectar trece (13) sistemas de enzimas en S. seminis y S. parvifolia, 10 en S. laevis, S. leprosula, S. selanica, S. aquminata, S. gibbosa, S. palembanica y S. pauciflora, 7 en S. paquetiana y 4 en S. johorensis. El uso del tampón de extracciónaprovechamiento de amortiguación W en combinación con el uso de sistemascon MC sistemas de aprovechamiento de tampones electroforéticos fue el que rindió los mejores resultados usandode usar pequeñas ramas y fueron casi que eran casi iguales a usar las hojas;, y una mejor resolución de ciertos sistemas de enzimas, tales como PER, PGI, SDH y MDH se obtuvo de las hojas. Los resultados obtenidos a partir de este estudio beneficiarán estudios posteriores sobre diversos aspectos, tales como la evaluación de la diversidad genética de las especies de Shorea y su mejoramiento genético. 
Deforestación, medios de vida y las condiciones previas para el manejo sostenible en Olancho, Honduras.

Sunderlin, W.D.

El crecimiento del hato de ganado nacional está contribuyendo a la rápida e inapropiada deforestación en Honduras. En el Departamento de Olancho, se desarrolló investigación de campo para comprender mejor este problema y para estimar las posibilidades del interés local en la protección de los bosques. Un reciente repunte en la rentabilidad de la ganadería es un presagio negativo para los bosques, pero tres factores compensadores podrían últimamente servir de base para el manejo forestal basado en la comunidtadrio. Primero, los residentes del área asignan tienen una mayor valorapreciación de a las funciones económicas y ecológicas de los bosques, de lo que se podría suponer, considerando el rápido avance de la deforestación. Segundo, la madera es una fuente importante de ingresos para la comunidad, por lo que podrían existir incentivos latentes para mantener las existencias en el largo plazo. Tercero, algunos residentes no regresarán a la ganadería, a pesar de su rentabilidad, tal vez por causa de su dependencia del mercadeo de la madera. Las políticas promulgadas en 1992, debilitan paulatinamente estos incentivos incipientes para la conservacióncustodia de los bosques. Mediante una reforma de las políticas, que le permita a los pequeños propietarios conservar y manejar sus recursos en el largo plazo, se puede disminuir la deforestación inapropiada.

Agriculture and Human Values, 1997, 14(1): 373-86.

Una metodología ex-post para medir la participación de las personas pobres en la forestería social: un ejemplo de Java, Indonesia.

Sunderlin, W.D.

Uno de los objetivos clave de la forestería social es involucrar a los pobres como beneficiarios de los proyectos. Es posible medir el grado de éxito de este objetivo mediante la recolección de datos socioeconómicos antes y después de la implementación del proyecto. Pero, este enfoque no se puede aplicar en los muchos sitios donde nunca se recolectaron datos exante. Este artículo propone una metodología para evaluar el grado de 
inclusión de los pobres en la forestería social, mediante el uso de datos expost únicamente. El análisis longitudinal se aplica aproxima utilizando variables socioeconómicas de "cambio lento" y mediante las regresiones logísticas. La metodología se ilustra con datos sobre el Programa de Forestería Social de Java.

Agroforestry Systems 37: 297-310.

\section{Agricultura Migratoria Cultivos Alternativos y Deforestación en Indonesia: los pasos para aclarar la confusión en el debate.}

Sunderlin, W.D.

El papel que desempeñan los cultivos alternativos en la deforestación en Indonesia ha sido un tema de gran debate. Algunos argumentan claman que este sistema agrícola es la principal causante de la pérdida de la cobertura forestal. Otros argumentanclaman que -lejos de ser un sistema dañinao- es un medio clave para la conservación y el manejo sostenible de los bosques remanentes. Ambos lados del debate están hablando de cosas diferentespor encima del otro, puesto que cada uno se refiere a distintosferentes sistemas agrícolas en extremos esquinas opuestaos de lo que se podría llamar "el medio continuumo del agricultura/forestalsistema agrícola forestal". Recientemente, se ha logrado cierto progreso en aclarar el significado de algunos términos, pero el debate todavía está confuso. Para entender mejor las causas y la extensión del cambio de la cobertura forestal en Indonesia, es necesario identificar claramente las diferentes formas en que las agencias afectan a los bosques y también definir términos y conceptos clave, tales como 'bosque', 'deforestación', 'degradación' y 'causalidad'. Con base en estas definiciones, entonces se podría llevar a cabo un análisis sobre el cambio de la cobertura forestal a lo largo del tiempo. (Inglés)

Red Forestal de Desarrollo Rural ODI Documento de la Red 21b. ODI, Londres, Reino Unido. 20 pág. (En inglés, francés y español). 
Organizaciones de pescadores y modelos de cogestiónmanejo conjunto: el caso de la Bahía de San Miguel, Filipinas.

Sunderlin, W.D. y Gorospe, M.L.G.

Recientes escritos han sostenidoreclamado que el manejo pesquero podría mejorarse mediante una regulación conjunta por parte de los cuerpos gubernamentales y los usuarios de los recursos, y a través de la devolución parcial de la autoridad de la gestión manejo deldesde el gobierno hacia las organizaciones de pescadores. Las Filipinas parecen brindar un óptimo ambiente institucional para el surgimiento de lla co-gestiónmanejo de las actividades pesqueras. El gobierno ha promulgado la legislación que les otorga a las organizaciones de pescadores un mayor papel en la gestión el manejo y ha habido una proliferación de las organizaciones de pescadores que se interesan por tomar una mayor responsabilidad sobre el manejo de los recursos. El caso de la Bahía de San Miguel muestra una situación en la cual han emergido dos formas paralelas de co-gestiónmanejo. La manera formal se basa principalmente en la iniciativa gubernamental y es pluralista. La manera informal se basa en la iniciativa de las organizaciones de pescadores y en la acción de los civiles, y está orientada hacia los intereses de los pequeños pescadores. LaEl co-gestiónmanejo efectivao a largo plazo requiere sobre todo tratar los mecanismos de los conflictos y la marginalización de los pequeños pescadores, así como integrar los esfuerzos en los dos aspectosde las dos formas.

Human Organization 56: 333-43.

\section{Aspectos económicos y políticos de la Imperata.}

Tomich, T.P., Kuusipalo, J., Menz, K. y Byron, N.

¿Deberían los formuladores de políticas -o alguien más- preocuparse por millones de hectáreas de praderas de Imperata? La respuesta depende del balance entre los costos de la conversión hacia otros usos y los beneficios netos producidos en el crecimiento económico, el alivio de la pobreza y la protección ambiental. La primera sección del documento sobre la economía de la Imperata establece el marco analítico para tratar este asunto y se basa en un mayor desarrollo de la literatura económica para 
considerar si el crecimiento y el alivio de la pobreza son objetivos conflictivos o complementarios. A pesar de que la evidencia es limitada, ésta sugiere que la agroforestería con base en los pequeños propietarios podría brindar el mismo crecimiento económico con un mayor alivio de la pobreza que las propiedades forestales a gran escala. Sin embargo, no existe un substituto para la evaluación de los proyectos de situaciones específicasestablecimientos específicos. La segunda sección del documento sobre las políticas de la Imperata revisa si las distorsiones de las políticas y las fallas del mercado brindan un marco de razonamiento suficiente para las intervenciones directas de las políticas que promuevan la siembra de árboles en las praderas de Imperata. Se presentan estimaciones de valores imputados a la fijación de carbono para aliviar el calentamiento global para la Acacia mangium y la agroforestería del caucho. La conclusión resume la agenda de investigación sobre políticas y examina el deseo y la viabilidad de la intervención de políticas para promover la fijación de carbono mediante la conversión de las praderas de Imperata a sistemas con base en los árboles.

Agroforestry Systems 36: 233-61.

Vegetación Australiana. En: J.C. Doran y Turnbull, J.W. (editores). Árboles y arbustos australianos: especies para la rehabilitación de terrenos y siembra de fincas en los trópicos, 19-37.

\section{Turnbull, J.W.}

El volumen está diseñado para brindar un texto de referencia para todos aquellos preocupados con la selección y el crecimiento de árboles y arbustos en las zonas rurales de los países en vías de desarrollo y en las partes más tropicales de Australia. Este primer capítulo resalta la singularidad de la vegetación australiana, su evolución y su ubicación como segmento típico de la flora mundial.

Las plantas leñosas madereras de Australia han sido destacadas por su singularidad desde el mismo momento de su descubrimiento y estudio por parte de botánicos Europeos. 'Qué tanCuán diferentes son' es un asunto de interpretación, pero un grado de singularidad deriva del hecho de que un $75 \%$ de las especies son endémicas de Australia y la vegetación leñosamaderera a 
lo largo de la mayor parte del continente está dominada por dos grandes géneros, los Eucaliptos y las Acacias. A un nivel taxonómico más alto, casi todas las familias angiospermas en Australia ocurren ampliamente en otras partes del mundo. El carácter especial debe ser explicado en términos de la geografía y del ambiente dentro de los cuales han evolucionado.

El prolongado aislamiento de Australia, seguido del rompimiento del supercontinente sureño de Gondwana ha contribuido enormemente a la singularidad de la vegetación. Australia estuvo aislada de los otros continentes durante por lo menos 60 millones de años. Durante este período, ocurrieron grandes cambios en el clima y el suelo, que fueron importantes para la evolución de la flora moderna.

Monografia de ACIAR No. 24. ACIAR, Canberra, Australia.

Acacia auriculiformis. En: Ibrahim, F.-H. y van der Maesen, L.J.G. (editores). Auxilliary plants in agriculture and forestry, 52-6.

Turnbull, J.W. y Awang, K.

Detalles sobre los usos, la botánica, la silvicultura, los recursos genéticos, la reproducción, prospectos y literatura para la Acacia auriculiformis.

PROSEA Handbook No. 11

Backhuys Publishers, Lieden, Holanda

Plantaciones de árboles tropicales para obtener productos de alto valor: una perspectiva del CIFOR.

Turnbull, J. W. y Byron, R. N.

Tradicionalmente, los bosques naturales hans brindado tanto madera de utilidad y de alto valor, como terrenos para el desarrollo, pero ahora se espera que contribuyan con objetivos económicos, sociales y ambientales más amplios. En los casos en que no se puedan obtener en forma sostenible el flujo de madnera y otros productos forestales a partir de los bosques naturales, las plantaciones forestales y los árboles en los sistemas agroforestales pueden producir muchos de los mismos productos. Conforme aumenta la presión de la población sobre los recursos naturales y la agricultura se vuelve más intensiva, laos 
perspectivas prospectos para un mayor desarrollo de la producción de madera de alto valor a partir de plantaciones a menor escala o lotes de bosquesáreas reservadas para la conservación del bosque que involucran a pequeños propietarios se están volviendo más factibles y atractivos. Sin embargo, surgen muchas preguntas a la investigación sobre tecnologías apropiadas y sobre los incentivos de políticas y económicos de las nuevas investigaciones, respecto a si los árboles deberían crecer en bloques más pequeños, más integrados con otros usos de la tierra, y con la participación directa de las personas de la localidad. Este documento describe brevemente el programa de investigaciones del CIFOR en las plantaciones tropicales y luego destaca algunos de los aspectos que afectarán la viabilidad de las plantaciones que se están desarrollando para obtener productos madereros de un más alto valor con referencia particular a Indonesia. Se brindan algunos puntos de vista sobre los mercados para las maderas duras provenientes de plantaciones en el Pacífico.

Documento presentado durante la Reunión Consultiva del ACIAR sobre Prioridades de Investigación para la Producción de Productos Forestales de Alto Valor que no son Dipterocarpáceas provenientes de Plantaciones en el Pacífico del Sudoeste, Cairns, 6 al 8 de mayo.

Eucalyptus urophylla. En: Ibrahim, F.-H. y van der Maesen, L.J.G. (editores). Auxilliary plants in agriculture and forestry, 140-4.

Turnbull, J.W. y Doran, J.C.

Detalles sobre los usos, la botánica, la silvicultura, los recursos genéticos, la reproducción, y perspectivasperpectivas de mejoramiento genético prospectos y literatura para ella Eucalyptus urophylla.

PROSEA Handbook No. 11

Backhuys Publishers, Lieden, Holanda 
Cambios y retos de la forestería internacional: preparáandoseción para el Siglo 21. En: Bachelard, E.P. y Brown, A.G. (editores). Preparándoseación para el Siglo 21. Memorias de la 4ta Conferencia Conjunta del Instituto de Forestales de Australia y el Instituto de Forestería de Nueva Zelanda, 21 al 24 de abril de 1997, Canberra, 13-19.

Vanclay, J.K.

Los recientes y anticipados cambios en la tecnología y en las instituciones ofrecen nuevos retos para la forestería en Australia y en el extranjero. Es fácil acomodar los cambios cuando se prevén, pero cuando los cambios no han sido anunciados, puede que sea mejor que los manejen aquellos con amplia experiencia y conocimiento actualizado. Por lo tanto, nos podemos preparar para los cambios mediante cursos seleccionados de refrescamiento y tratandoprocurando activamente de ampliar nuestra experiencia. Es muy probable que el papel de Australia a nivel regional y global, como base del conocimiento, como bodega genética y como comercializadora de la madera se volverá más importante en el futuro. Australia y Nueva Zelandia tienen mucha práctica y experiencia a la que deberían de aspirar nuestros cercanos vecinos del norte, en especial respecto al aprovechamiento forestal de impacto reducido, gerenciamanejo de la investigación y planificacióneación de la conservación.

IFA, Canberra, Australia.

FLORES: un modelo para evaluar opciones de uso de la tierra en la frontera del bosque. En: Memorias, Avances en la Metodología y los Programas de Cómputo para los Sistemas de Apoyo a las Decisiones, 5 al 7 de setiembre de 1997, Laxenburg, Austria.

Vanclay, J.K.

Los asuntos de políticas son centrales para el manejo de los recursos naturales, pero las consecuencias de las políticas bien intencionadas no siempre son obvias, en especial para el uso de la tierra en las zonas de fronteracolindantes de los bosques. Se propone un modelo para predecir la conducta de los individuos en las comunidades forestales cercanas a las fronteras del bosque, y los impactos resultantes y las respuestas del ecosistema. La hipótesis subyacente es que los individuos se comportan 
en forma racional para maximizar su utilidad y, por lo tanto, que su comportamiento bajo diferentes escenarios se puede predecir. El modelo FLORES (Sistema de Visualización de Recursos Orientados a las Tierras Forestales) será espacialmente explícito, permitiendo fuertes pruebas empíricas. Inicialmente, el modelo probará hipótesis propuestas por investigadores asociados y ayudará a identificar las brechas y las deficiencias en el conocimiento existente. Finalmente, debería ayudarle a los formuladores de políticas y a los planificadores a entender mejor las consecuencias de sus propuestas y se podría implementar como un juego educativo (cf. SimCity, SimIsle, etc.).

http://www.iiasa.ac.at / marek/ftppub/Pubs/dss97/vanclay.pdf

¿Cómo obtener el máximo provecho de los datos de su parcela permanente? En: Memorias de la Conferencia de la IUFRO 1.07/4.01/4.02.03 sobre Estudios de Crecimiento en los Bosques del Trópico Húmedo en áfrica, 11 al 15 de noviembre de 1996, Kumasi, Ghana, 43-8.

Vanclay, J.K.

Se presenta un catálogo de ideas para el análisis gráfico de datos sobre crecimiento, con la esperanza de estimular eun análisis más imaginativo. Los gráficos pueden ser particularmente reveladores, puesto que el ojo humano es muy bueno para detectar patrones. Se brindan sugerencias para confeccionar gráficos más efectivos y análisis más perspicaces.

IUFRO, Viena, Austria y CIFOR, Bogor, Indonesia.

Introducción a la estimación de los rendimientos forestales. En: Métodos para la Estimación de los Rendimientos de Cosecha. Memorias de un Seminario, Villefranche-sur-Mer, 24 al 27 de octubre de 1994. Eurostat, JRP-Ispra, DG VI y FAO, 265-71.

Vanclay, J.K.

Este documento presenta la predicción del crecimiento forestal y de rendimientos y su lugar en el manejo forestal y en la formulación de políticas. El rango de bienes y servicios que brindan los bosques, aparte de la madera, se destacannotan como un factor importante en estos 
modelos para formular prescripciones y políticas. Se discute el extenso papel de la predicción en las tres áreas de las emisiones antropogénicas, la socioeconomía y la ecología conforme se relacionan con el manejo y la planificacióneación forestal. Los modelos de rendimientos de las plantaciones y los modelos de crecimiento para bosques mixtos se presentan junto con sugerencias de términos alternativos y técnicas de verificación para reducir los problemas de la interpretación.

ECSC-EC-EAEC, Luxemburgo.

Hacia una valoración más rigurosa de la biodiversidad. En: Bachmann, P., Köhl, M. y Päivinen, R. (editores). Valoración de la biodiversidad para una mejor planificación forestal. Memorias de la Conferencia sobre la Valoración de la Biodiversidad para la Planificación Forestal , 7 al 11 de octubre de 1996, Monte Veritá, Suiza, 211-32.

Vanclay, J.K.

Por lo general, la biodiversidad se define en forma deficiente y se mide de maneraen forma subjetiva, lo que da por resultado estimaciones ineficaces y ambiguas. Las fortalezas y deficiencias de las técnicas de valoración prevalecientes se estudian mediante una revisión de literatura seleccionada. Se utilizan analogías con inventarios forestales para sugerir opciones para una valoración de la biodiversidad más eficiente y rigurosa. Las técnicas, tales como la de variable-probabilidad y los muestreos con base en modelos, especialmente cuando se usan junto con modelosajes lineales generalizados, ofrecen alternativas eficientes a lasde valoraciones más tradicionales basadas en cuadrantes y en parcelas anidadasempaquetadas. Los métodos Bayesianos ofrecen el ámbito para combinar el conocimiento experto y local con las muestras formales, y garantizar la investigación posterior. Se brindan sugerencias para posteriores investigaciones.

Forestry Sciences Series 51, Kluwer, Dordrecht, Holanda. 
TROPIS, el sistema de información sobre el crecimiento de los árboles y parcelas permanentes. En: Memorias de la Conferencia de la IUFRO 1.07/4.01/4.02.03 sobre Estudios de Crecimiento en los Bosques del Trópico Húmedo en áfrica, , 11 al 15 de noviembre de 1996, Kumasi, Ghana, 200-04. (Inglés)

Vanclay, J.K.

TROPIS, el Sistema de Información Sobre el Crecimiento de los árboles y Parcelas Permanentes, contiene cinco elementos: (1) una red de personas dispuestas a compartir datos sobre parcelas permanentes e información sobre el crecimiento de los árboles (servicio brindado a través de boletines y fuentes de información en la siguiente página WEB: http://www.cgiar..org/cifor/research/tropis.html o disponible del CIFOR), (2) un índice a o una meta- base de datos de personas e instituciones que mantienen datos sobre parcelas permanentes, (3) un sistema de manejo de bases de datos (MIRA) para brindar un manejo de datos más eficiente, (4) un sistema (WORLD) para identificar sitios comparables en otras regiones, permitiendo la utilización de datos de cualquier otro lugar cuando no exista información local sobre crecimiento, y (5) un sistema de inferencia (PLANTGRO) que permita que se hagan estimaciones sobre crecimiento en ausencia de datos empíricos. La mayoría de estos componentes todavía se están desarrollando, pero los primeros dos elementos están funcionando. El índice de la meta base de datos actualmente contiene referencias de 10.000 parcelas con 2.000 especies aportadas por 100 colaboradores y está creciendo a una tasa de 1.000 parcelas por mes. Las búsquedas de la base de datos son bienvenidas y se le pueden dirigir al autor.

IUFRO, Viena, Austria y CIFOR, Bogor, Indonesia.

\section{Evaluación de modelos de crecimiento forestal.}

Vanclay, J.K. y Skovsgaard, J.P.

El modelo de evaluación efectiva no es un simple procedimiento singular, sino que comprende varios pasos interrelacionados que no se pueden separar el uno del otro o del propósito y del proceso de la construcción del modelo. Llamamos la atención hacia varios procesos estadísticos y gráficos que pueden asistir en la calibración y evaluación de modelos, con 
un énfasis especial en aquellos que son útiles para la modelación del crecimiento de los bosques. Proponemos un marco de cinco pasos, para examinar las propiedades lógicas y biológicas, propiedades estad'sísiticas estadísticas, las características de los errores, residuosales y análisis de sensibilidad. Se pueden realizar evaluaciones empíricas con datos utilizados para ajustar calzar el modelo y con datos adicionales que no han sido utilizados previamente. Enfatizamos que la validez de las conclusiones derivadas de todas estas valoraciones depende de la validez de las suposiciones subyacentes tanto del modelo como de la evaluación. A lo largo de la construcción y la evaluación, se deberían tener presentes estos principios.

Ecological Modelling 98: 1-12.

Utilización de los atributos no funcionales de las plantas para cuantificar la productividad del sitio y los patrones de crecimiento en bosques mixtos.

Vanclay, J.K., Gillison, A.N. y Keenan, R.N.

Los modelos de crecimiento forestal forman uno de los varios requisitos previos para el manejo sostenible. La complejidad de los bosques húmedos tropicales significa que por lo general existe poca información objetiva para clasificar los sitios y las especies para el modelaje del crecimiento y la predicción de los rendimientos. La clasificación basada en las características morfológicas observables podría ser un útil substituto útil para o un suplemento para para otras alternativas. Este estudio investigó la utilidad de los atributos funcionales de las plantas (PFA) para los sitios y la clasificación de las especies. Los PFA describen una planta en términos de su sistema de apoyo fotosintético y vascular, y la suma de los PFA individuales para todas las especies de una parcela proveen un eficiente resumen de las características de la vegetación en el sitio. Las observaciones preliminares sugirieron que el resumen de los PFA también podría indicar la productividad del sitio, o que se pueden utilizar PFA específicos para agrupar especies para modelar el crecimiento y el rendimiento. Los datos de 17 parcelas permanentes en los bosques tropicales del Norte de Queensland se utilizaron para probar estas observaciones preliminares. Se completaron proformas de PFA estándares para cada parcela, en enero de 1995, y se examinaron las relaciones entre los 
PFA, la productividad de los sitios y patrones específicos de crecimiento, utilizando análisis de discriminación, regresiones lineales y pruebas estadísticas estándares. Los resultados indican que el tamaño promedio de las hojas y la incidencia de las especies con la inclinación vertical de las hojas (más de $30{ }^{\circ}$. sobre la horizontal) están significativamente correlacionados con la productividad del sitio. De los PFA evaluados, cinco elementos parecen ofrecer una base útil para agrupar las especies para el modelaje: tamaño e inclinación de las hojas, un índice de bifurcación (p.e., altura relativa a la primera horquilla o rompimiento del tallo principal), o la presencia de lenticelas y tejido clorofíilicoloso en el tallo principal. La naturaleza restringida de nuestra base de datos limita los comentarios sobre la utilidad general del método, pero los resultados sugieren queque se garantizan los estudios posteriores sobre los PFA están garantizados.

Forest Ecology and Management 94: 149-63.

La caza de primates y el manejo de bosques: el caso de los propietariosfinqueros forestales de lban en Kalimantán Occidental, Indonesia.

Waldley, R.L., Colfer, C.J. Pierce y Hood, I.G.

Para los finqueros forestales de Iban en Kalimantán Occidental, Indonesia, la caza es una parte importante de su economía de subsistencia y, como tal, se convirtió en el centro de un estudio como parte de un proyecto de conservación en la Reserva de Vida Silvestre de Danau Sentarum. En este documento, examinamos la caza de primates no humanos por parte de los finqueros de Iban, en comparación con otros grandes mamíferosmanuales. Analizamos tasas de encuentro y captura, comparaciónrando de encuentros, viajes de caza y cantidad de animales. La información sobre los hábitats cazados muestran la importancia de los bosques secundarios y de viejo crecimiento. También se examinan las actitudes de los pobladores de Iban, sus preferencias de caza juegos y tabúes. El significado de estos resultados se discute en relación con la amenaza de la vida silvestre a causa del aumento del uso de armas de fuego, de la población humana y de la destrucción del hábitat, mostrando que se podría contribuir a la conservación promoviendo o resaltando ciertos aspectos de los sistemas agroforestales tradicionales de los habitantes de Iban. 
Mecanismos de deforestación: una repasoencuesta.

Wibowo, D.H. y Byron, R.N.

Una gran cantidad de modelos económicos publicados sobre deforestación tropical, se revisan en cuatro categorías:

- un enfoque Neo-Maltusiano, por lo general confuso e impreciso, en términos de procesos causales, que identifica ve a a las presiones de la población como la causa subyacente de la deforestación tropical;

- las que se centran en los errores del gobierno - en especial, en las políticas gubernamentales mal dirigidas en otros sectores que dan como resultado una deforestación excesiva e inapropiada; políticas sectoriales (p.e., prohibición de la exportación de troncos); y la falla general de instituciones supervisoras de gobiernogobernabilidad, incluyendo la corrupción. Este enfoque le pone un gran énfasis a los efectos de las intervenciones gubernamentales;

- un enfoque microeconómico que considera la racionalidad económica de la tala del bosque desde la perspectiva de los finqueros, y explica como varias formas de los errores del mercado, p.e. derechos de propiedad pobremente definidos, contratos de aprovechamiento forestal mal diseñados y subestimación de los beneficios de los bosques a nivel local, regional y global, todos contribuyen a la deforestación; y

- un énfasis macroeconómico que explora los vínculos que se afirma que existen entre la deuda y la deforestación, y que conduce hacia los cambios trueques de deuda por naturaleza propuestos como un medio para reducir la tasa de deforestación en los países en vías de desarrollo. Los autores concluyen que tanto los errores del gobierno como el análisis microeconómico son particularmente relevantes para comprender los procesos actuales de deforestación y las opciones de políticas en Indonesia.

Documento de Trabajo No. 19: Programa de Economía, Ecología y el Ambiente, Universidad de Queensland, Brisbane, Australia. 32 pág. 
Deforestación y acumulación de capital: lecciones de la región alta del Alto Kerinci, Indonesia.

Wibowo, D.H., Tisdell, C.A. y Byron, R.N.

El estudio describe un caso en el cual la conducta de los agricultores que acumulan capital, en vez de su pobreza, como se presume usualmente, da como resultado la deforestación. Se llevaron a cabo trabajos de campo en la región del Aaltao de Kerinci den la isla de Sumatraera, en Indonesia. Se realiza un análisis financiero de los flujos de "ingresos netos" que reciben los agricultores por la deforestación. Debido a que los terrenos forestales pueden ser "capturados" y privatizados mediante la tala y que lasu subsecuente agricultura, tienen la capacidad de producir altos retornos financieros para los agricultores, así como proveerles de capital suficiente adecuado para financiar su siguiente tala forestal. Dicha capacidad permite que los agricultores sin propiedades se conviertan en propietarios. También la tala forestal les permite a los agricultores ser dueños de un "bono de maduración a largo plazo" en la forma de una plantación de canela. La pobreza les impide a los agricultores más pobres que puedan deforestar, y las decisiones de talar los bosques quedan casi siempre en manos de los agricultores más establecidos. Los excedentes financieros provenientes del exterior del sector forestal y del agrícola también se utilizan para financiar la tala forestal.

Documento de Trabajo No. 8: Programa de Economía, Ecología y el Ambiente, Universidad de Queensland, Brisbane, Australia. 19 pág.

Toma de decisiones entre diversos intereses: el uso de escenarios futuros en las políticas de manejo forestal local: una propuesta metodolóogíica propuesta. Documento presentado en el Seminario sobre Forestería Comunitaria en la Encrucijada: Reflexiones y Dirección Futura en el Desarrollo de la Forestería Comunitaria, 17 al 19 de julio de 1997.

Wollenberg, $E$.

Este documento propone una metodología para reforzar el proceso de la formulación de políticas en el manejo forestal local, definido aquí como la participación de las personas que viven cerca del bosque en actividades que tienen la intención de mantener o aumentar los bosques y mejorar el 
bienestar de los habitantes localesas personas locales. El método permite que los diferentes actores identifiquen en forma colectiva sus necesidades futuras y las respuestas de políticas apropiadas mediante la construcción de escenarios futuros. El énfasis del método está más en el proceso de la generación de tales escenarios, a través de la consulta a los actores, que en el producto de los escenarios o modelos utilizados para producirlos.

Bangkok, Tailandia, Centro Regional de Capacitación en Forestería Comunitaria (RECOFTC). 9 pág.

Sostenibilidad social. En: Borrini-Feyerabend, G. y Buchan, D. (editores). Beyond fences: seeking social sustainability in conservation. Volumen 2, 115-17.

Wollenberg, E. y Colfer, C.J.P.

En discusiones sobre asuntos de conservación, es común oír el término 'sostenibilidad social' o escuchar referencias a los 'aspectos sociales de la sostenibilidad'. A pesar de que estos conceptos se utilizan con frecuencia, rara vez se encuentran definidos. Los autores ofrecen tres definiciones que pueden ser usadas por separado o combinadas. La sostenibilidad social se puede definir como el mantenimiento del bienestar de las personas (con énfasis en las personas que más dependen de los recursos), las acciones de las personas para mantener los recursos o el mantenimiento de beneficios equitativos a través de las generaciones. Es necesario ser claro respecto a cuál definición se utiliza, de manera que se pueda tener una mutua comprensión de lo que se va a lograr mediante la sostenibilidad social.

Los autores enfatizan que cualquier definición sobre sostenibilidad es intrínsecamente relativa y está restringida por los límites del tiempo, del lugar y de las personas que están siendo consideradas. En cualquier situación, es importante mantener la flexibilidad de la visión propia sobre lo que es la sostenibilidad social y estar abierto a revisar ese punto de vista con base en circunstancias cambiantes y/o diferentes.

UICN, Gland, Suiza. 
Fragmentación forestal y biodiversidad forestal: el caso de las áreas de conservación de tamaño intermedio.

Zuidema P. A., Sayer A. J. y Dijkman W.

Comprender los efectos de la fragmentación forestal sobre la biodiversidad es esencial para la conservación forestal exitosa y eficiente. Cuatro factores pueden causar la pérdida de la biodiversidad en los fragmentos forestales: el efecto de muestreos no aleatorios del bosque original, tamaño reducido del bosque, aislamiento y efectos de los bordes. Una revisión de 58 documentos sobre los efectos de la fragmentación forestal revela que las conclusiones generales de la investigación sobre fragmentaciones están distorsionadas debido a un enfoque sobre los pájaros, en los efectos de tamaño en vez de aislamiento, y sobre la presencia de especies, en vez del tamaño de las poblaciones. Quizás el resultado más importante es que el conocimiento actual sobre los efectos de la fragmentación se basa principalmente en estudios de pequeños fragmentos ( $<10$ hectáreas). Estos están dominados por los efectos de los bordes, no pueden contener poblaciones viables para muchas especies y son raramente el foco de programas de conservación. Los estudios de pequeños fragmentos no se pueden extrapolar a áreas protegidas de mayor tamaño. Puede que la conservación de áreas de mediano tamaño, ubicadas estratégicamente sea una opción más eficiente para la conservación de la biodiversidad, dadas las limitaciones financieras, sociales y logísticas. Se necesitan más investigacióones sobre el manejo de los bosques que sean representativaos del tamaño de las verdaderas áreas de protección (p.e., $>10.000-100.000$ ha) y deberían enfocarse en los procesos biológicos y los inducidos por el hombre los humanos que determinan la persistencia de las especies.

Environmental Conservation 23 (4) 290-297, 1996. 
Para ordenar las publicaciones del CIFOR, favor contactar a:

Communications Unit

CIFOR

P.O. Box 6596 JKPWB

Jakarta 10065

Indonesia

teléfono: $+62(251) 622622$

facsímil: + 62 (251) 622100

dirección electrónica: cifor@cgiar.org

Para ordenar las publicaciones en venta, sírvase enviarnos los detalles de su tarjeta de crédito (nombre del tarjetahabiente, número de la tarjeta de crédito, fecha de vencimiento y firma). Aceptamos única mente Visa y Master Card. 